\title{
ESTIMATED CONTRIBUTION OF HEMOGLOBIN AND MYOGLOBIN TO NEAR INFRARED SPECTROSCOPY
}

by

\section{MICHELLE L DAVIS}

B.S., Kansas State University, 2005

\author{
A THESIS \\ submitted in partial fulfillment of the requirements for the degree \\ MASTER OF SCIENCE \\ Department of Kinesiology \\ College of Arts and Sciences \\ KANSAS STATE UNIVERSITY \\ Manhattan, Kansas
}

2009

Approved by:

Major Professor

Dr. Thomas Barstow 


\begin{abstract}
Near infrared spectroscopy is currently routinely used to assess tissue (muscle) oxygenation at rest and during exercise. While most investigators assume that hemoglobin $([\mathrm{Hb}])$ is the major contributor to the responses seen during exercise, the relative contribution of myoglobin ([Mb]) to the NIRS signals remains controversial. PURPOSE: a) To calculate the range of light absorbing potential (LAP) of hemoglobin and myoglobin in mammalian skeletal muscle at rest based on analysis of published chemical and morphometric data in humans and other mammals (Part 1), and b) use the information in a) to interpret changes in total $[\mathrm{Hb}+\mathrm{Mb}]$ from NIRS during exercise (Part 2). METHODS: Part 1: Information was retrieved from five published studies with regard to capillary density $\left(\#\right.$ caps $\left./ \mathrm{mm}^{2}\right)$ and $[\mathrm{Mb}]$ in skeletal muscle of human, horse and rat. Preference was given to studies in which both measurements were provided for the same muscles. $[\mathrm{Hb}]$ in skeletal muscle was estimated as a function of capillary density, $[\mathrm{Hb}]$ in systemic blood, and the ratio of capillary-to-systemic hematocrit at rest and during exercise. Part 2: Changes in total $[\mathrm{Hb}]+[\mathrm{Mb}]($ as $\mathrm{t}[\mathrm{Hb}+\mathrm{Mb}])$ from published NIRS data obtained from human subjects performing cycling or knee extension exercise were interpreted in the context of the results of Part 1. RESULTS: Part 1: Individual group mean values for skeletal muscle $[\mathrm{Mb}]$ in the literature ranged from $0.25-0.67 \mathrm{mM}$ in human samples, with a similar range for muscles of the rat hindlimb; horse limb muscles tended to be higher (up to $1.0 \mathrm{mM}$ ). Capillary densities ranged from $\sim 200$ to $600 \mathrm{caps} / \mathrm{mm}^{2}$ in human and rat muscles, and up to 800 caps $/ \mathrm{mm}^{2}$ in horse muscle. Assuming a resting capillary hematocrit of $22 \%$ and 4 fold greater LAP for each mole $[\mathrm{Hb}]$ vs $[\mathrm{Mb}]$, the resulting estimation of capillary $[\mathrm{Hb}]$ ranged from $\sim 0.03$ to
\end{abstract}


$0.09 \mathrm{mM}$ in human and rat muscles, and up to $\sim 0.13 \mathrm{mM}$ in horse muscles. The results suggest that $[\mathrm{Mb}]$ could contribute $\sim 50-70 \%$ of the total LAP at rest in human skeletal muscle. Part 2:

With exercise, total heme by NIRS can increase $\geq 30 \%$ in individual human subjects. Assuming this increase reflects only increased $[\mathrm{Hb}]$, this fits well with the observed increase in capillary hematocrit with exercise. CONCLUSIONS: 1) In skeletal muscle at rest, [Mb] is likely to be at least as significant a light absorbing heme as is $[\mathrm{Hb}]$ in most mammalian muscles, including the human leg. 2) Observed increases in $\mathrm{t}[\mathrm{Hb}+\mathrm{Mb}]$ with NIRS during exercise can be explained by an increase in capillary hematocrit, even in the presence of significant $[\mathrm{Mb}]$. 


\section{Table of Contents}

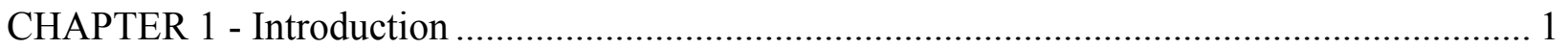

CHAPTER 2 - Review of Literature ........................................................................... 4

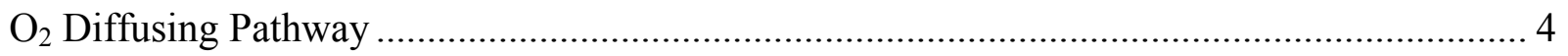

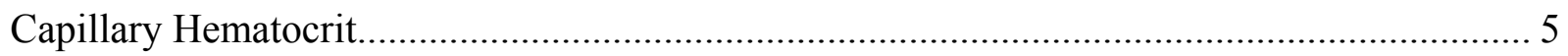

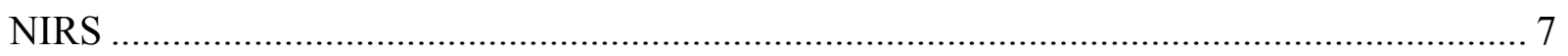

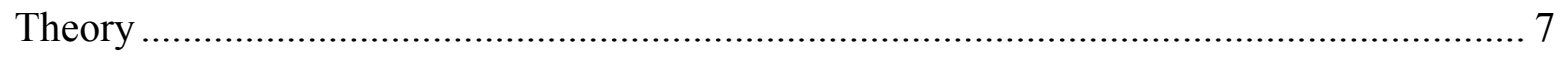

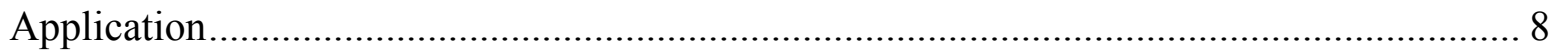

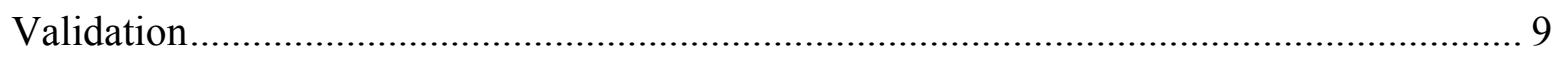

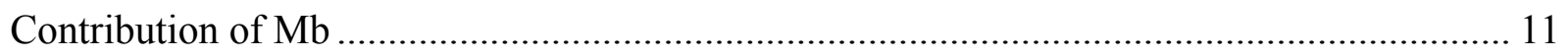

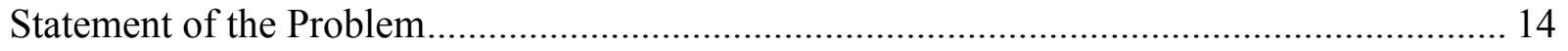

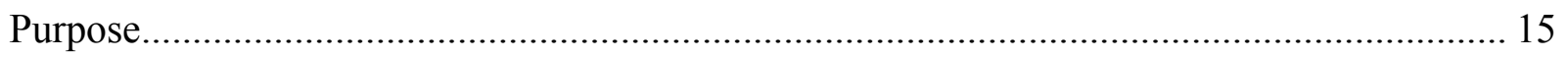

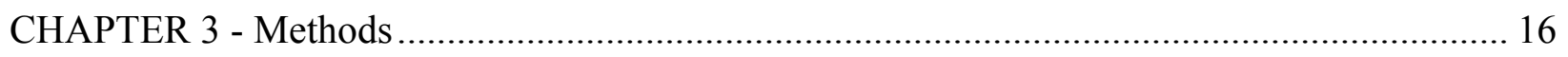

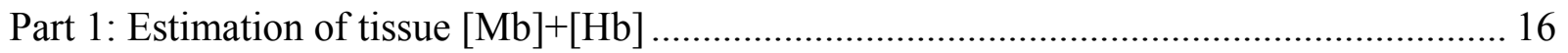

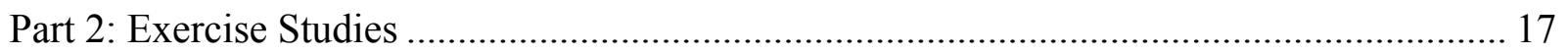

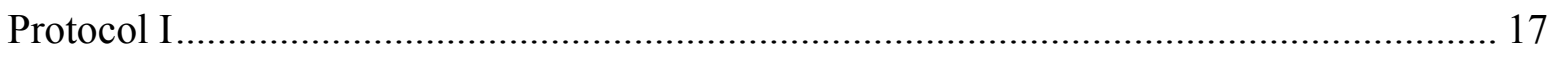

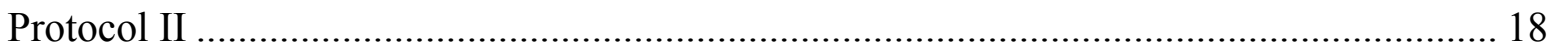

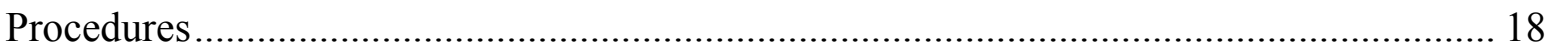

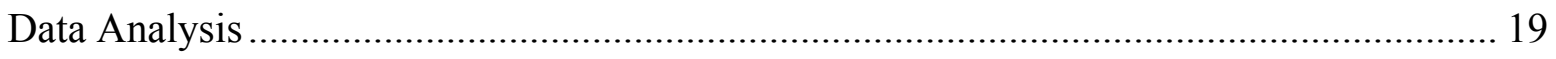

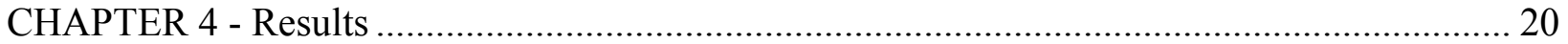

Figure 4-1 Concentration and light absorbing potential (LAP) for different capillary densities

Figure 4-2 LAP of $[\mathrm{Hb}]$ and $[\mathrm{Mb}]$ calculated for several mammalian species and muscles .... 24

Figure 4-3 Calculated vs measured $[\mathrm{Mb}+\mathrm{Hb}]$ concentrations and light absorbing potential

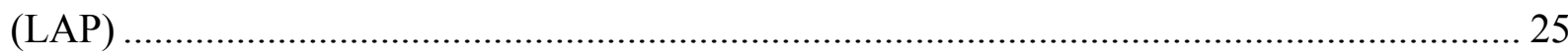

Figure 4-4 The effect of changes in $[\mathrm{Hb}]$ on changes in total $[\mathrm{Hb}+\mathrm{Mb}]$ during exercise ....... 26

Table 4-1 Percent change in total $[\mathrm{Hb}+\mathrm{Mb}]$ during knee extension and incremental cycling tests 


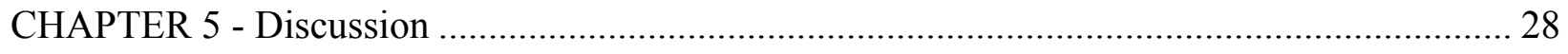

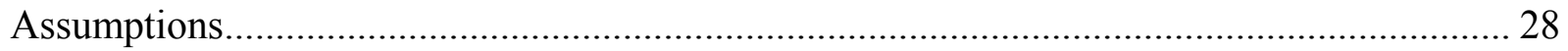

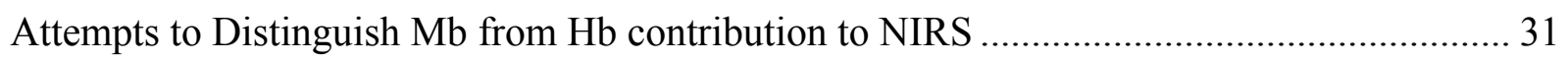

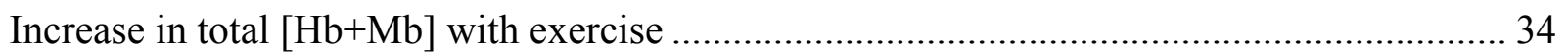

Implications of increased $[\mathrm{Mb}]$ contribution to NIRS ................................................. 35

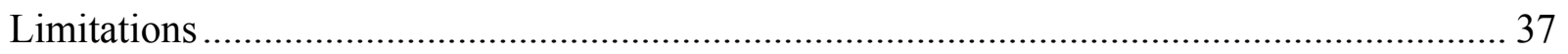

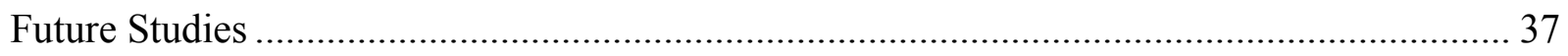

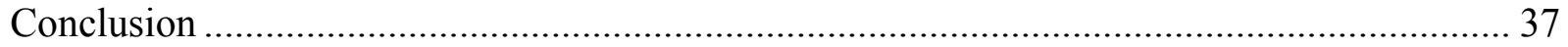

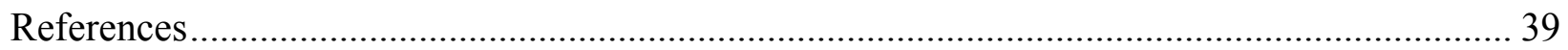




\section{CHAPTER 1 - Introduction}

NIRS is a non-invasive, optical technique that uses near infrared light to estimate brain, blood and tissue oxygenation, making NIRS ideal for use in human studies. This technique is based on the fact that hemoglobin $(\mathrm{Hb})$ and myoglobin $(\mathrm{Mb})$ can exist in two forms, oxygenated (oxy-[Hb] and oxy-[Mb]) and deoxygenated (deoxy-[Hb] and deoxy-[Mb]), each with its own absorption spectra. The application of the Beer-Lambert law was significant in the theoretical development and subsequent ability to make absolute quantitative measures with NIRS (Rolfe, 2000).

The ability to assess the quantitative contribution of $\mathrm{Hb}$ and $\mathrm{Mb}$ to the NIRS signal has been a challenging and controversial task. On the one hand, it has often been assumed that both the NIRS signal at rest, and changes in the signal during exercise, are derived primarily from $\mathrm{Hb}$ ( $>90 \%$ ), while $\mathrm{Mb}$ is thought to contribute minimally $(<10 \%)$ to the signal (Mancini et al, 1994, Seiyama et al, 1987). In contrast, other studies suggest that Mb may be the predominant contributor to the NIRS signal (Tran et al, 1999, Richardson et al, 1995, Mole et al, 1999). Several factors may affect tissue $[\mathrm{Hb}]$, and thus its relative contribution to NIRS, including muscle capillary volume and the average hematocrit within that vascular volume. Capillary volume and skeletal muscle $[\mathrm{Mb}]$ likely remain constant from rest to exercise. However, capillary hematocrit has been observed to be less than that of the systemic circulation at rest (Kindig and Poole, 2001, Russell et al, 2003, Kindig and Poole, 1998, Barbee and Cokelet, 1971, Klitzman and Duling, 1979) and increases towards systemic hematocrit with increased flow, such as seen with muscle contractions (Kindig and Poole, 2001 and Desjardins and Duling, 
1990). Thus, these factors may have a drastic affect on the relative contributions of $\mathrm{Mb}$ and $\mathrm{Hb}$ to NIRS.

The increase in $\mathrm{VO}_{2}$ at the onset of exercise relies on several factors, one of them being the ability to widen the $\mathrm{O}_{2}$ gradient from capillary to mitochondria (Tran et al, 1999). It has been suggested that the cell can modulate its own $\mathrm{PO}_{2}$ gradient with $\mathrm{Mb}$ facilitated diffusion contributing significantly to oxygen transport to the mitochondria (Gayeski et al, 1988, Wittenberg, 1970, Wittenberg and Wittenberg, 2003, Mole et al 1999). However, assessing the capillary to mitochondria $\mathrm{PO}_{2}$ gradient is exceptionally challenging in humans. NIRS has been used to try and assess noninvasively changes in tissue (i.e., $\mathrm{Hb}$ and $\mathrm{Mb}$ ) saturation, so as to infer changes in extra- and intracellular $\mathrm{PO}_{2}$. Two other examples of the use of NIRS to estimate dynamic physiological processes include the measurement of muscle $\mathrm{VO}_{2}$ (De Blasi et al., 1994) and the estimation of capillary blood flow ( $\left.\mathrm{Q}_{\text {cap }}\right)$ (Ferreira et al., 2005). In both of these methodologies, the assumption is made that the NIRS signal reflects primarily or exclusively $\mathrm{Hb}$ saturation status. If the NIRS signal contains significant contribution from $\mathrm{Mb}$, the appropriateness of both methods must be reevaluated.

Due to a) the potentially significant role of $\mathrm{Mb}$ in oxygen transport from capillary to mitochondria (Richardson et al, 2006, Richardson et al, 2001, Mole et al, 1999, Groebe and Thews, 1990)(but see also Ordway and Garry, 2004), and b) the assumption in the above methodologies that $\mathrm{Hb}$ is the primary/exclusive source of the NIRS signal, the contribution of $\mathrm{Mb}$ to the NIRS signal needs to be re-examined. Therefore, the purposes of this study were to a) using the relative concentrations of $[\mathrm{Mb}]$ and $[\mathrm{Hb}]$ in mammalian skeletal muscle based on published chemical and morphometric data, estimate the resulting potential contributions of $\mathrm{Hb}$ and $\mathrm{Mb}$ to the NIRS signal (expressed as light absorbing potential (LAP)) (Part 1), and b) use the 
information in a) to interpret changes in total $[\mathrm{Hb}+\mathrm{Mb}]$ by NIRS during exercise (Part 2). Using appropriate assumptions regarding muscle capillary density, systemic $[\mathrm{Hb}]$, relative contribution of $\mathrm{Hb}$ and $\mathrm{Mb}$ molecules to the LAP based on heme groups, average skeletal muscle [Mb] and capillary hematocrit at rest, the contribution of $\mathrm{Hb}$ and $\mathrm{Mb}$ to the signal can be calculated. We predicted that $\mathrm{Mb}$ will contribute significantly more to the NIRS signal in human skeletal muscle than the often assumed value of $\leq 10 \%$ (Seiyama et al, 1988), perhaps contributing closer to $50 \%$ of the NIRS signal. However, the increases in total $[\mathrm{Hb}+\mathrm{Mb}]$ concentration reported with exercise in humans would still have to be explained as an increase in capillary [Hb], which will effectively place a limit on how much of the signal can originate from tissue [Mb]. 


\section{CHAPTER 2 - Review of Literature}

\section{$\mathrm{O}_{2}$ Diffusing Pathway}

$\mathrm{VO}_{2}$ is facilitated by gradual drops in oxygen pressure $\left(\mathrm{PO}_{2}\right)$ from the lungs to muscle cells. Pressure gradients allow for the diffusive movement of oxygen from one medium to the next. From the alveoli, to the arteries, to the capillaries and then finally to the muscle cell, $\mathrm{PO}_{2}$ drops $\sim 70 \mathrm{mmHg}$ at rest. The largest drop in pressure at rest is from the arteries to the capillaries $(\sim 60-65 \mathrm{mmHg})$. At rest the $\mathrm{PO}_{2}$ in the muscle cell has been calculated to be $\sim 34$ $\mathrm{mmHg}$ (Richardson et al, 2006), which dramatically drops during exercise to $2-5 \mathrm{mmHg}$ (Richardson et al, 2006, Richardson et al, 2001, Mole et al, 1999).

Richardson et al (2006) used ${ }^{1} \mathrm{H}-\mathrm{MRS}$ to measure Mb desaturation in skeletal muscle at rest, and from this calculated intracellular $\mathrm{O}_{2}$ partial pressure. In normoxic conditions there was a deoxy-Mb signal of $\sim 9 \%$, which predicted a $\mathrm{PO}_{2}$ of $34 \mathrm{mmHg}$ at rest. With potentially $91 \%$ of $\mathrm{Mb}$ being saturated at rest it provides immediate availability of oxygen which can be utilized by the mitochondria at the onset of exercise. The immediate utilization of oxygen from $\mathrm{Mb}$ causes a drop in intracellular $\mathrm{PO}_{2}$ at the onset of exercise. While there is a small drop in capillary $\mathrm{PO}_{2}$ from rest $(44 \mathrm{mmHg})$ to exercise $(37.5 \mathrm{mmHg})$, the larger drop in intracellular $\mathrm{PO}_{2}$ from rest ( $\sim 34 \mathrm{mmHg}$ ) to peak exercise (2-mmHg) causes a large net increase in the $\mathrm{PO}_{2}$ gradient, increasing oxygen diffusion from the capillary to the mitochondria (Richardson et al, 2006).

Although Mb may be an important component to facilitate oxygen diffusion to the cell, is it vital? Knockout mice lacking myoglobin have been genetically engineered to assess the importance of $\mathrm{Mb}$. Many of the mice suffered severe, lethal cardiovascular defects during 
embryonic development. However, those that survived the womb showed no critical cardiovascular or energetic defects. The mice grew normally and were able to perform treadmill exercise to exhaustion and responded normally in hypoxic conditions. There were, however, noticeable cardiovascular adaptations in these knockout mice, including increased cardiac and skeletal muscle capillary density, increased hematocrit and increased cardiac output. Knockout mice also demonstrate an increased expression of hypoxia-induced genes coding for vascular endothelial growth factor and nitric oxide synthase. The increased expression of these genes may provide the basis for the cellular adaptations seen in knockout mice (Ordway and Garry, 2004, Garry et al, 1998, Godecke et al, 1999). While these mice are able to function normally without $\mathrm{Mb}, \mathrm{Mb}$-facilitated oxygen diffusion may be important in delivering oxygen to the mitochondria. Oxygen is highly insoluble in water and the ratio of Mb-bound oxygen to free oxygen in the cell is $\sim 30: 1$ (Wittenberg and Wittenberg, 2003). This would indicate that a large portion of oxygen diffusion to the mitochondria is facilitated by $\mathrm{Mb}$. Oxygenated $\mathrm{Mb}$ may also influence the level of nitric oxide within a cell, which may control the rate of capillary oxygen delivery and the rate of oxygen utilization by cytochrome oxidase (Wittenberg and Wittenberg, 2003). Ordway and Garry (2004) described some of the important roles of Mb such as providing a reservoir of oxygen, buffering intracellular oxygen concentration, facilitating intracellular oxygen transport and inactivating $\mathrm{NO}$ and other reactive oxygen species. It is clear that $\mathrm{Mb}$ plays significant functional roles in cardiac and skeletal muscle tissue.

\section{Capillary Hematocrit}

Capillary recruitment has been proposed for close to a century as one of the mechanisms that may explain the increase in diffusing capacity $\left(\mathrm{DO}_{2}\right)$ from rest to exercise in skeletal muscle (Krogh, 1919, Renkin, 1983, Honig et al, 1980 and Clark et al, 2008). Many of the methods 
used by those that support the concept of capillary recruitment have several flaws such as using opaque dye which makes it difficult to see RBCs, underestimating the complexity of the tortuous three dimensional capillary network or not actually viewing the capillary network, which may lead to inaccurate conclusions. On the other side of the capillary recruitment debate, direct observation of capillary beds reveals that a majority of the capillaries $(\sim 85 \%)$ have flow at rest in healthy skeletal muscle (Poole et al, 1997, Kindig and Poole, 2001).

If capillary recruitment is not the mechanism for increasing muscle capillary $\mathrm{DO}_{2}$ during exercise, then alternative mechanisms need to be explored. At the onset of exercise RBC velocity increases within $\sim 1 \mathrm{sec}$ (Kindig et al, 2002). RBC flux is also increased at the onset of exercise, but more gradually, taking $\sim 10 \mathrm{sec}$. Capillary tube hematocrit $\left(\mathrm{Hct}_{\mathrm{cap}}\right)$ also increases, closely following the RBC flux time course. An increase in capillary tube hematocrit may be linked to an increase in muscle blood flow, which would increase oxygen availability for muscle tissue. Kindig et al (2002) found a significant increase in Hct $_{\text {cap }}$ from rest (15\%) to contraction $(20 \%)$. Further, they found more than $80 \%$ of the capillaries at rest supported RBC flow. This increase in Hct $_{\text {cap }}$ may be what is interpreted in many studies (Krogh, 1919, Renkin, 1983, Honig et al, 1980 and Clark et al, 2008) as capillary recruitment. Consistent with these observatons, Richardson et al (2003) measured RBC velocity and flux in skeletal muscle and calculated capillary hematocrit from these two measurements in rats with chronic heart failure (CHF) and a healthy control group. The control group had flowing RBCs in $\sim 84 \%$ of capillaries at rest while in the CHF rats it was $\sim 66 \%$. Contractions did not cause significant recruitment of new capillaries in the muscle for either group. However, contractions did cause an increase in RBC

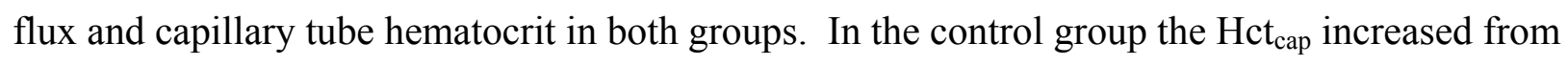


$16 \%$ at rest to $\sim 21 \%$ after contractions ( $32 \%$ increase), while the CHF group saw an increase from $\sim 18 \%$ at rest to $\sim 23 \%$ after contractions.

\section{NIRS}

\section{Theory}

Near Infrared Spectroscopy (NIRS) is a non-invasive, optical technique that uses near infrared light to estimate tissue oxygenation. This technique is based on the fact that hemoglobin $(\mathrm{Hb})$ and myoglobin $(\mathrm{Mb})$, the oxygen carrying components in blood and muscle tissue respectively, can exist in two forms, an oxygenated (oxy-[Hb] and oxy-[Mb]) and a deoxygenated (deoxy-[Hb] and deoxy-[Mb]) state, each with its own absorption spectra. Horecker (1943) was the first to measure the optical absorption spectra of oxy-[Hb] and deoxy$[\mathrm{Hb}]$, and validated the application of the Beer-Lambert law to solutions of $\mathrm{Hb}$ derivatives.

The Beer-Lambert law was significant in the theoretical development and subsequent ability to make absolute quantitative measures with NIRS. The Beer-Lambert law is expressed as:

$$
\mathrm{A}=\log \left(\mathrm{I}_{0} / \mathrm{I}\right)=\varepsilon[\mathrm{C}] \mathrm{L}
$$

where A is the light absorption, $\mathrm{I}_{\mathrm{o}}$ is the intensity of the incident light, $\mathrm{I}$ is the intensity of light after passing through material, $\varepsilon$ is the molar extinction coefficient, which is wavelength dependent, $[\mathrm{C}]$ is the concentration and $\mathrm{L}$ is the distance (pathlength) from light source to detector (Rolfe, 2000). By measuring the attenuation of the interrogating light, and with knowledge of $\varepsilon$ and $\mathrm{L}$, it is possible to determine the concentration $[\mathrm{C}]$ of a substance in absolute terms.

There are other variables to consider when estimating concentrations with NIRS, particularly in the vasculature and muscle tissue. In tissue there are several surfaces that the 
interrogating light may encounter that have a different refractive index than the background material, causing the beam to scatter throughout the tissue. The light photon gets refracted away from the direct transmit-receive path of the NIRS probe, and some of the light may be lost or travel a longer path before being detected. To account for scattering the Beer-Lambert law may be modified:

$$
\mathrm{A}=\log \left(\mathrm{I}_{0} / \mathrm{I}\right)=\varepsilon[\mathrm{C}] \mathrm{L} * \mathrm{DPF}+\mathrm{G}
$$

which includes corrections for scattering losses $(\mathrm{G})$ and increased optical path length due to scattering (differential path length factor, DPF) (Owen-Reece et al, 1999). The modified BeerLambert law permits determination of a change in concentration of the substance being measured due to a change in the attenuation of the light in a scattering medium such as tissue. However, quantification of the concentration depends on being able to measure DPF. One of the techniques used to measure DPF in tissue is frequency domain (FD) spectroscopy (Hueber et al, 2001).

\section{Application}

There are different types of spectrometers available for use. There is a continuous wave spectrometer that measures only relative changes in tissue saturation. There are semiquantitative devices that give a specific value of tissue oxygenation by assuming constant scattering throughout the medium. The more sophisticated techniques (including frequency modulated or time resolved models) are also available and they are able to measure scattering and thus give absolute values for tissue oxygenation (Rolfe, 2000, Owen-Reece et al, 1999).

FD spectroscopy modulates the intensity of the interrogating light making it possible to continuously monitor the average path of the NIR light photons as they travel in the tissue (Rolfe, 2000). The light detected exiting the tissue goes through a phase shift, while the AC and 
DC intensities decrease (Rolfe, 2000). Spectrometers have been developed with multiple light sources and wavelengths to increase the accuracy of measurements with NIRS. The OxiplexTS, ISS (Champaign, IL) is one type of FD spectrometer that consists of eight light emitting diodes and one detector fiber bundle. The diodes operate at two wavelengths, four diodes for each specific wavelength. Source detector separations are 2.0, 2.5, 3.0 and $3.5 \mathrm{~cm}$. Measurement of the optical path length at each wavelength permits the calculation of absolute concentrations of deoxy-[Hb+Mb] and oxy-[Hb+Mb]. Using multiple wavelengths also allows for a more accurate correction of the path length variations that occur in tissue due to scattering. Wavelengths in the vicinity of 690-850 $\mathrm{nm}$ have commonly been used for measuring changes only in oxy-[Hb+Mb] and deoxy-[Hb+Mb] (Mancini et al, 1994, Chance et al, 1992, Grassi et al, 1999, Ferreira et al, 2005).

\section{Validation}

Mancini et al (1994) attempted to validate NIRS use in humans using a continuous wave dual frequency $(760-800 \mathrm{~nm})$ spectrometer. They found that skin blood flow and increases in body and skin temperature had minimal effect on the qualitative NIRS responses. There was also a linear relationship between forearm venous $\mathrm{O}_{2}$ saturation levels and absorption by the NIRS indicating NIRS was able to provide an index of tissue oxygenation.

Wilson et al (1989) used NIRS on canine gracilis to determine if NIRS was adequate to detect changes in skeletal muscle oxygen availability and observed that the changes in the NIRS signal closely followed the changes in the gracilis venous $\mathrm{Hb} \mathrm{O}_{2}$ saturation. Next, they used NIRS to assess skeletal muscle oxygenation in patients with heart failure. A progressive decrease in $[\mathrm{Hb}+\mathrm{Mb}]$ oxygenation was measured in the right vastus lateralis during exercise in both healthy subjects and heart failure subjects, but this occurred at significantly lower 
workloads in the heart failure subjects. Wilson et al (1989) concluded that NIRS is an adequate, non-invasive method to measure skeletal muscle oxygenation in healthy and heart failure subjects.

McDonald et al (1999), however, came to a different conclusion regarding the ability of NIRS to measure skeletal muscle oxygenation. Saturation levels measured in the right vastus lateralis with NIRS did not follow femoral venous oxygen saturation measurements during exercise in normoxic and hyperoxic breathing conditions. The only condition that showed a significant correlation was during the hypoxic breathing condition; normoxic and hyperoxic conditions showed NIRS oxygenation levels increasing while femoral venous oxygen saturation decreased. Due to the marked differences in NIRS oxygenation and femoral venous oxygenation, McDonald et al (1999) concluded that NIRS was not an accurate assessment of venous blood oxygenation during exercise. It should be noted, however, that there are several limitations to this study. NIRS measurements and femoral venous $\mathrm{O}_{2}$ blood samples were taken from opposite legs, leaving the potential for a systematic difference between the legs that could affect the results. The probe was removed and replaced over the vastus lateralis for each gas breathing condition which may have altered probe placement for each test. It is also unclear how $\mathrm{Mb}$ may contribute to oxygen saturation in the various gas breathing conditions. Finally, femoral venous $\mathrm{PO}_{2}$ will reflect the integration of venous drainage from all tissue beds of the leg, not just the vastus lateralis. Thus, it is not surprising that the authors did not see a correlation between the NIRS and venous blood samples.

The effect of skin blood flow on the validity of NIRS has been a recurring issue. Buono et al (1995) and Davis et al (2006) assessed the effect of skin blood flow on NIRS measurements. Using local heating (Buono et al, 1995, Davis et al, 2006)) and whole body heating (Davis et al, 
2006), an increase in skin blood flow occurred that contributed significantly to continuous wave NIRS measurements. However, the NIRS device and placement in these studies may not have been adequate to properly measure skeletal muscle oxygenation. The light-source detector distance may have been too close to allow the light to penetrate beyond the skin and fat into the skeletal muscle being measured (Quaresima and Ferrari, 2006, Ferrari et al, 2006). Buono et al (1995) and Davis et al (2006) used a probe with distances of $\sim 2.5 \mathrm{~cm}$ and $2 \mathrm{~cm}$ apart, respectively. A distance of $4-5 \mathrm{~cm}$ is recommended for measuring tissue oxygenation to increase the sensitivity of the measurement and increase the probability of looking beyond the tissue surface to deeper muscle. The shorter distances of $2-2.5 \mathrm{~cm}$ in the above studies resulted in predominantly skin blood volume being the major contributor to the NIRS signals.

\section{Contribution of $\mathbf{M b}$}

A fundamental question with NIRS is to what extent $\mathrm{Mb}$ may or may not contribute to the signal. Conflicting results have been obtained from the few studies which have attempted to ascertain the relative contributions of tissue $\mathrm{Mb}$ and microvascular $\mathrm{Hb}$ to NIRS signals. On the one hand, several studies have concluded that $\mathrm{Mb}$ contributes minimally to the signal (e.g., Mancini et al, 1994, Seiyama et al, 1988, Wilson et al, 1989), while others found significant contributions of Mb (e.g., Tran et al, 1999, Richardson et al, 1995).

Seiyama et al (1988) measured the contribution of Mb to the NIRS signal by measuring the absorption changes in the rat hindlimb perfused with and without blood. The change in absorbance at $700-780 \mathrm{~nm}$ in rat hindlimbs using the RBC-free perfusate was less than $10 \%$ of that with blood containing $\mathrm{RBCs}$, indicating $\mathrm{Mb}$ contributed a small amount to the overall signal for this specific preparation. 
Wilson et al (1989) measured muscle blood flow in canine gracilis muscle and concluded there was no Mb contribution. They used NIRS on the muscle with no flow and compared it to the muscle with flow after being treated with ethyl hydrogen peroxide, which prevents $\mathrm{Mb}$ from desaturating. There was no significant difference between the two NIRS signals, leading the authors to conclude $\mathrm{Mb}$ does not significantly contribute to NIRS.

In humans, several studies have measured $\mathrm{Mb}$ desaturation with ${ }^{1} \mathrm{H}-\mathrm{MRS}$, and compared these results to changes in NIRS, with mixed results. Mancini et al (1994) used ${ }^{1} \mathrm{H}-\mathrm{MRS}$ to monitor desaturation of $\mathrm{Mb}$ while concurrently monitoring $[\mathrm{Hb}+\mathrm{Mb}]$ desaturation qualitatively with continuous wave dual frequency NIRS in four subjects. High levels of $\mathrm{Hb}$ desaturation with submaximal plantar flexion exercise were observed with no $\mathrm{Mb}$ deoxygenation detected. NIRS detected additional deoxygenation after cuff occlusion at $700-780 \mathrm{~nm}$ in one of the subjects, which the authors attributed to a small change in Mb oxygenation. At peak exercise, deoxy$[\mathrm{Mb}]$ was seen in three subjects while the NIRS desaturation reached $71 \%$. This led the authors to conclude the NIRS signal is derived primarily from $\mathrm{Hb}$ and not $\mathrm{Mb}$.

Conversely, Tran et al (1999) used ${ }^{1} \mathrm{H}-\mathrm{MRS}$ and NIRS to measure deoxy-[Mb] and [Hb] changes during cuff occlusion and plantar flexion. With ${ }^{1} \mathrm{H}-\mathrm{MRS}$ there was no deoxy-[Mb] signal at rest, but with exercise the deoxy-[Mb] signal began to emerge and further increased with cuff occlusion. Deoxy-[Hb] was detected with ${ }^{1} \mathrm{H}-\mathrm{MRS}$ and rapidly reached a steady state, contributing $\sim 10 \%$ to the signal. While ${ }^{1} \mathrm{H}$-MRS detected a significant desaturation of $\mathrm{Mb}$ during exercise and cuff occlusion, deoxy-[Hb] did not emerge until after cuff occlusion. Deoxygenation in the muscle was detected with NIRS in this study, but in contrast to Mancini et al (1994) the NIRS signal observed in the study of Tran et al (1999) followed the deoxy-[Mb] kinetics more closely than deoxy-[Hb] kinetics. 
However, these studies have some limitations that call for an alternate interpretation of the data. ${ }^{1}$ H-MRS has commonly been used to measure Mb levels in tissue (Mancini et al, 1994, Tran, 1999, Richardson et al, 1995). Tran et al (1999) found a significant increase in the $\mathrm{Mb}$ signal with ${ }^{1} \mathrm{H}-\mathrm{MRS}$ during cuff occlusion and plantar flexion exercise. One explanation for the lack of Mb desaturation with cuff occlusion in the study of Mancini et al (1994) is that the blood flow was not completely occluded by the cuff, resulting in an increase in total[ $\mathrm{Hb}+\mathrm{Mb}]$ and possibly preventing $\mathrm{Mb}$ from becoming desaturated. The lack of $\mathrm{Hb}$ detected by ${ }^{1} \mathrm{H}-\mathrm{MRS}$ in Tran et al (1999) may be explained by Wang et al (1993), who showed that only $16 \%$ of Hb was NMR visible in a suspension of intact RBCs. This may have led to a significant underestimation of the changes in $\mathrm{Hb}$ saturation in Tran et al (1999). The methodological issues in both of these studies prevent specific conclusions regarding the contribution of Mb to the NIRS signal from being drawn.

The specific muscle being measured with NIRS may also determine the amount of $\mathrm{Mb}$ detected. Muscle fiber type and/or oxidative capacity may influence the level of $\mathrm{Mb}$ in the tissue: highly oxidative fibers tend to have higher amounts of mitochondria and capillary density, while lower oxidative fibers exhibit the opposite. Hickson et al (1981) measured the Mb in several different rat muscles: the plantaris, soleus, red vastus lateralis and white vastus lateralis. The white vastus lateralis contained $\sim 0.034 \mathrm{mM}$ of $\mathrm{Mb}$, the red vastus lateralis contained $\sim 0.34$ $\mathrm{mM}$ of $\mathrm{Mb}$ and the soleus contained $\sim 0.25 \mathrm{mM}$ of Mb. In Seiyama et al (1988) the NIRS probe was most likely measuring the superficial fibers of the muscle, in this case the white region of the vastus lateralis of the rat hindlimb. These data suggest that the white vastus of the rat is an inappropriate representation of $\mathrm{Mb}$ contribution to the NIRS signal, especially when comparing it to human muscles. 
Richardson et al (1995) used ${ }^{1} \mathrm{H}-\mathrm{MRS}$ to measure $\mathrm{Mb}$ deoxygenation. The maximal deoxy-Mb signal was derived from the average signal during minutes 9 and 10 of vascular cuff occlusion, where it was assumed $\mathrm{Mb}$ was completely deoxygenated. Before the onset of exercise there was no apparent deoxy-[Mb] signal. During unweighted knee extensor exercise the deoxy$\mathrm{Mb}$ signal increased to $38 \%$ of the maximal deoxy-[Mb] signal obtained from previous vascular cuff occlusion. As exercise intensity increased to $\sim 50 \% \max \mathrm{VO}_{2}$, the deoxy-[Mb] signal increased rapidly, up to $50 \%$ within $20 \mathrm{sec}$ and this level was maintained to maximum work output. Mole et al (1999) used ${ }^{1} \mathrm{H}-\mathrm{MRS}$ and cuff occlusion to obtain the maximum deoxy-[Mb] signal, similar to Richardson et al (1995). With exercise Mb desaturated progressively as work output increased and deoxy-[Mb] reached $\sim 50 \%$ at $\mathrm{VO}_{2 \text { peak }}$. Richardson et al (1995) found that $\mathrm{Mb}$ desaturated rapidly and reached a steady state at $\sim 50 \% \mathrm{VO}_{2 \max }$, while Mole et al (1999) found that $\mathrm{Mb}$ desaturation had a linear relationship with $\mathrm{VO}_{2}$ and work output up to $100 \% \mathrm{VO}_{2}$

peak. However, both of these papers reported significant levels of Mb deoxygenation, leading to the question of how much Mb may actually contribute to the NIRS signal.

\section{Statement of the Problem}

Previous research has supported the assumption that $\mathrm{Mb}$ only contributes $\leq 10 \%$ to the total $[\mathrm{Hb}+\mathrm{Mb}]$ signal measured by NIRS. However, there are significant flaws with these studies, as previously discussed. In contrast, other studies and analyses suggest that $\mathrm{Mb}$ may contribute more to the NIRS signal than previously thought, possibly even more than $\mathrm{Hb}$. Due to the potentially significant role of $\mathrm{Mb}$ in oxygen transport from capillary to mitochondria (Richardson et al, 2006, Richardson et al, 2001, Mole et al, 1999, Groebe and Thews, 1990, Garry et al, 1998) the contribution of $\mathrm{Mb}$ to the NIRS signal needs to be re-examined. 


\section{Purpose}

Using appropriate assumptions regarding muscle capillary density, systemic [Hb], relative contribution of $\mathrm{Hb}$ and $\mathrm{Mb}$ molecules to the light absorbing potential (LAP) based on heme groups, average skeletal muscle $[\mathrm{Mb}]$ and capillary hematocrit at rest, the contribution of $\mathrm{Hb}$ and $\mathrm{Mb}$ to the signal can be calculated. We predicted that $\mathrm{Mb}$ would be found to contribute significantly more to the NIRS signal than the often assumed value of $\leq 10 \%$ (Seiyama et al, 1988), perhaps contributing closer to $50 \%$ of the NIRS signal, particularly in human muscle. However, the increases in total $[\mathrm{Hb}+\mathrm{Mb}]$ concentration reported with exercise in humans must still be explained as an increase in capillary $\mathrm{Hb}$, which will effectively place a limit on how much of the signal can originate from tissue $\mathrm{Mb}$.

The purposes of this study were to a) using the relative concentrations of $\mathrm{Mb}$ and $\mathrm{Hb}$ in mammalian skeletal muscle based on published chemical and morphometric data, estimate the resulting potential contributions of $\mathrm{Hb}$ and $\mathrm{Mb}$ to the NIRS signal (expressed as light absorbing

potential (LAP)) (Part 1), and b) use the information in a) to interpret changes in total [ $\mathrm{Hb}+\mathrm{Mb}]$ by NIRS during exercise in human studies (Part 2). 


\section{CHAPTER 3 - Methods}

The present study was divided into two parts. In Part 1, we utilized values for capillary densities and tissue $[\mathrm{Mb}]$ from several published studies to calculate the relative contribution of $[\mathrm{Hb}]$ and $[\mathrm{Mb}]$ to NIRS in mammalian skeletal muscle. An equation was developed to calculate muscle capillary $[\mathrm{Hb}]$ and compared to reported tissue $[\mathrm{Mb}]$ values. In Part 2, the calculated contribution of $[\mathrm{Hb}]$ and $[\mathrm{Mb}]$ to NIRS from the present study was compared to NIRS measurements of total $[\mathrm{Hb}+\mathrm{Mb}]$ from previous studies from this lab (Ferreira et al 2005, Lutjemeier et al, 2008). Both protocols had been approved by the Institutional Review Board for Research Involving Human Subjects at Kansas State University.

\section{Part 1: Estimation of tissue [Mb]+[Hb]}

The first project utilized values of tissue $[\mathrm{Mb}]$ and capillary density from the literature for a variety of mammalian skeletal muscles, including human, in order to estimate the concentration of tissue $[\mathrm{Mb}]$ and capillary $[\mathrm{Hb}]$, which then allowed for calculation of the contribution of $\mathrm{Hb}$ and $\mathrm{Mb}$ to the total NIRS signal (expressed as light absorbing potential (LAP)). Capillary volume in human skeletal muscle was estimated using the equations and values from Richardson et al (1994):

$$
\text { Cap Vol } \left.=\left[\left(28.3 \mu \mathrm{m}^{2}\right)\left(\text { number of cap } \cdot \mathrm{mm}^{2}\right)\right] / 1 \mathrm{~mm}^{2} * 1.2 \text { (eq. } 2\right)
$$

where $28.3 \mu^{2}$ represents the average capillary area in human skeletal muscle (Richardson et al, 1994). For the number of capillaries $\cdot \mathrm{mm}^{-2}$, a range of $200-500 \mathrm{cap} \cdot \mathrm{mm}^{-2}$ was used (Richardson et al 1994), which allowed for multiple theoretical totals of capillary volume to be calculated and compared. 
The following equation was developed to obtain muscle capillary $[\mathrm{Hb}]$ concentrations, from which LAP was estimated:

$$
\text { Total } \left.[\mathrm{Hb}]_{\mathrm{cap}}=10 \mathrm{mmol} / \mathrm{L} \text { of blood } * \text { Capillary volume } * 0.5 \operatorname{Hct}_{\text {cap }} \text { (eq. } 1\right)
$$

where $10 \mathrm{mmol}$ of hemoglobin per liter of blood was an average of hemoglobin values listed for men and women (Marieb 2004). The 0.5 Hct $_{\text {cap }}$, was used to reflect the reduction in capillary tube hematocrit, relative to that for systemic hematocrit. An average systemic hematocrit value of 45\% (Merck Manual 2003; Kindig and Poole 2001) was used and an average resting capillary tube hematocrit of 22\% was assumed (Kindig and Poole 2001, Russell et al 2003, Kindig and Poole 1998). In order to calculate LAP the fact that there are 4 heme units per hemoglobin molecule but only one heme per myoglobin molecule was taken into consideration. Thus, 4 times as much light can be absorbed per $\mathrm{Hb}$ molecule compared to $\mathrm{Mb}$, which will affect the contribution of each to the NIRS signal.

These $[\mathrm{Hb}]_{\text {cap }}$ values were compared to $[\mathrm{Mb}]$ values that were obtained from van BeekHarmsen et al. (2004), who measured myoglobin levels in skeletal muscles from male and female humans with and without disease. From their data an average of $0.5 \mathrm{mM}[\mathrm{Mb}]$ was used as the default value to compare to the estimated $[\mathrm{Hb}]$.

\section{Part 2: Exercise Studies}

\section{Protocol I}

The first protocol was an incremental ramp cycling exercise test (Ferreira et al, 2005), performed by nine healthy, physically active subjects, seven males and two females $(24.7 \pm 6.3$ yrs, $67.9 \pm 12.2 \mathrm{~kg}$ ). Each subject visited the lab two times for testing with at least $48 \mathrm{hrs}$ between each test day. Incremental cycling exercise was performed on an electronically braked cycle ergometer (Corival 400, Lode, The Netherlands). The exercise protocol began with 4 min 
of baseline cycling at $20 \mathrm{~W}$ at a cadence of either 60 or $100 \mathrm{rpm}$. This was followed by a ramp increase in exercise intensity of $15-30 \mathrm{~W} / \mathrm{min}$ until volitional fatigue was reached or cadence fell below 55 or $95 \mathrm{rpm}$, as appropriate, for 5-10 s. On the second visit, the same protocol was performed at the alternative cadence. Throughout each test, NIRS was used to measure total $[\mathrm{Hb}+\mathrm{Mb}]$ levels in the right vastus lateralis.

\section{Protocol II}

The second protocol (Lutjemeier et al, 2008) enrolled eight subjects; seven male and one female volunteer $(23 \pm 2 \mathrm{yrs}, 175 \pm 9 \mathrm{~cm}$ and $71 \pm 13 \mathrm{~kg})$. All the subjects performed one leg, upright knee extension exercise on a specially built leg ergometer. A strap was placed around the subject's ankle and attached to a pneumatic cylinder through a cable pulley system. Each subject completed two work bouts at a contraction frequency of 40 contractions per minute. A moderate work bout was performed at $30 \%$ of peak work rate and a heavy work bout was performed at $80 \%$ of peak work rate. There was at least 20 min of rest between the two work bouts. Tissue oxygenation by NIRS was measured on the right rectus femoris throughout each test.

\section{Procedures}

Skeletal muscle oxygenation was estimated by a frequency domain multidistance (FDMD) NIRS system (OxiplexTS, ISS, Champaign, IL). The FDMD NIRS has 8 light emitting diodes using wavelengths of 692 and $834 \mathrm{~nm}$ and one detector fiber bundle. The source-detector separations were $2.0,2.5,3.0$ and $3.5 \mathrm{~cm}$. The probe was positioned longitudinally on the belly of the vastus lateralis (Protocol I) or the rectus femoris (Protocol II) for each subject. The probe was bonded to the skin (Skin-Bond, Smith and Nephew, Largo, FL) and held in place with Velcro ${ }^{\circledR}$ straps. The probe placement was marked during the first test to assure that the probe 
was placed at the same site during subsequent testing. The NIRS measured absolute concentrations of oxy- and deoxy- $[\mathrm{Hb}+\mathrm{Mb}]$ expressed in $\mu \mathrm{M}$. Measures of the total $[\mathrm{Hb}+\mathrm{Mb}]$ concentration were then calculated with the following equation: Total $[\mathrm{Hb}+\mathrm{Mb}]=\mathrm{oxy}-[\mathrm{Hb}+\mathrm{Mb}]$ + deoxy- $[\mathrm{Hb}+\mathrm{Mb}]$.

\section{Data Analysis}

Percent change of the total $[\mathrm{Hb}+\mathrm{Mb}]$ signal was calculated from thirty second averaging

for both protocols. For Protocol I the percent change of the total $[\mathrm{Hb}+\mathrm{Mb}]$ signal was calculated from baseline $(20 \mathrm{~W})$ exercise to peak $\mathrm{VO}_{2}$ for both the $60 \mathrm{rpm}$ and $100 \mathrm{rpm}$ tests. For Protocol II the percent change of the total $[\mathrm{Hb}+\mathrm{Mb}]$ signal was calculated from rest to end exercise. Group means \pm standard deviations were calculated for both protocols. 


\section{CHAPTER 4 - Results}

Figure 4-1 shows the concentration and LAP of $\mathrm{Hb}$ and $\mathrm{Mb}$ at varying theoretical capillary densities ranging from $200-500 \mathrm{cap} / \mathrm{mm}^{2}$. An assumed [Mb] of $0.5 \mathrm{mM}$ (van BeekHarmsen et al, 2004) was used with all capillary volumes. The top, lighter portions of the columns represent the $\mathrm{Hb}$ contribution and the lower, darker portions represent the $\mathrm{Mb}$ contribution. The estimated concentration of muscle $\mathrm{Hb}$ at rest was $0.034 \mathrm{mM}$ at $200 \mathrm{cap} / \mathrm{mm}^{2}$, $0.06 \mathrm{mM}$ at $350 \mathrm{cap} / \mathrm{mm}^{2}$ and $0.086 \mathrm{mM}$ at $500 \mathrm{cap} / \mathrm{mm}^{2}$. The resulting percent contribution of $[\mathrm{Hb}]$ and $[\mathrm{Mb}]$ to the total heme concentration was $[\mathrm{Hb}]=6 \%$ and $[\mathrm{Mb}]=94 \%$ at $200 \mathrm{cap} / \mathrm{mm}^{2}$, $[\mathrm{Hb}]=11 \%$ and $[\mathrm{Mb}]=89 \%$ at $350 \mathrm{cap} / \mathrm{mm}^{2}$ and $[\mathrm{Hb}]=15 \%$ and $[\mathrm{Mb}]=85 \%$ of the total heme at $500 \mathrm{cap} / \mathrm{mm}^{2}$. The percent contribution of $\mathrm{Hb}$ and $\mathrm{Mb}$ to the LAP calculated from the above values yielded a $\mathrm{LAP}$ of $\mathrm{Hb}=22 \%$ and $\mathrm{Mb}=78 \%$ at $200 \mathrm{cap} / \mathrm{mm}^{2}, \mathrm{Hb}=32 \%$ and $\mathrm{Mb}=68 \%$ at $350 \mathrm{cap} / \mathrm{mm}^{2}$ and $\mathrm{Hb}=41 \%$ and $\mathrm{Mb}=59 \%$ at $500 \mathrm{cap} / \mathrm{mm}^{2}$.

The relative LAP of vascular $\mathrm{Hb}$ and tissue $\mathrm{Mb}$ for individual muscles are shown in Fig 4-2. Hb contributions are the lighter portion of the column and $\mathrm{Mb}$ the darker portion of the column. $\mathrm{Mb}$ in these mammalian muscles represented $\sim 50-60 \%$ of the total LAP across the different muscles with the exception of the LAP estimated for the rat hindlimb, $\sim 30 \%$, in which the capillary density was taken from Farrelly et al (1992) and [Mb] was used from Sillau et al (1977), i.e., the values were not taken from the same animal.

Figure 4-3 shows a comparison between the intermediate estimations of $[\mathrm{Hb}]$ and $[\mathrm{Mb}]$ concentrations and LAP from this paper for human muscle and the corresponding data from Seiyama et al (1988) for the rat hindlimb. In the present study, the estimated concentration of 
$\mathrm{Hb}$ at a capillary density of $350 \mathrm{cap} / \mathrm{mm}^{2}$ was $0.06 \mathrm{mM}$, while a $\mathrm{Mb}$ concentration of $0.5 \mathrm{mM}$ was assumed. The resulting percent contribution of the total heme concentration was $[\mathrm{Hb}]=$ $11 \%$ and $[\mathrm{Mb}]=89 \%$. From this, LAP was calculated, with $[\mathrm{Mb}]$ contributing $68 \%$ to the LAP, while $[\mathrm{Hb}]$ contributed $32 \%$. In contrast, Seiyama et al (1988), using blood and Hb-free perfusates, found that $\mathrm{Hb}$ contributed $90 \%$ to the LAP of the NIRS signal in the rat hindlimb. Based on this, the calculated relative concentration of $[\mathrm{Mb}]$ in the rat hindlimb would be $30 \%$ and $[\mathrm{Hb}] 70 \%$.

Table 4-1 shows in human subjects the change in total $[\mathrm{Hb}+\mathrm{Mb}]$ of the rectus femoris during constant work rate knee extension exercise (Lutjemeier et al, 2008) and of the vastus lateralis during incremental cycling exercise (Ferreira et al, 2005). During knee extension exercise the change in total $[\mathrm{Hb}+\mathrm{Mb}]$ from rest ranged from $6.9-34.5 \%$. The subject with the greatest change in total $[\mathrm{Hb}+\mathrm{Mb}]$ during the knee extension exercise $(34.5 \%)$ was a national caliber triathlete who likely had a greater capillary volume and density and smaller adipose tissue thickness. During the cycling tests the change in total $[\mathrm{Hb}+\mathrm{Mb}]$ at $60 \mathrm{rpm}$ ranged from $0.3-30 \%$ and at $100 \mathrm{rpm}$ ranged from 4.6-19.6\%, both from a baseline of $20 \mathrm{~W}$.

Figure 4-4 demonstrates how the increase in total $[\mathrm{Hb}+\mathrm{Mb}]$ with exercise in humans can be interpreted based on the present calculations using a capillary density of $350 \mathrm{cap} / \mathrm{mm}^{2}, 22 \%$ $\mathrm{Hct}_{\text {cap }}$ at rest and $[\mathrm{Mb}]$ concentration of $0.5 \mathrm{mM}$. The average increase in total $[\mathrm{Hb}+\mathrm{Mb}]$ seen with knee extension exercise (20.4\%) and incremental cycling at $60 \mathrm{rpm}$ and $100 \mathrm{rpm}(10.9 \%)$ and the largest change in knee extension exercise (34.5\%) were used from Table 1. Assuming a constant muscle $[\mathrm{Mb}]$ concentration, the increase in total $[\mathrm{Hb}+\mathrm{Mb}]$ with exercise would reflect an increase in $[\mathrm{Hb}]$ (as $\left.\mathrm{Hct}_{\mathrm{cap}}\right)$ in the microvasculature. With incremental cycling, this would reflect almost a 33\% increase in tissue $[\mathrm{Hb}]$, which would represent an increase in the relative 
contribution to the LAP from $32 \%$ to $39 \%$, while during knee extension exercise the [Hb] would increase by approximately $50 \%$, increasing the LAP of $\mathrm{Hb}$ from $32 \%$ to $44 \%$. Note that the LAP for $\mathrm{Mb}$ would show a corresponding decrease as $[\mathrm{Hb}]$ increased. These increases are physiologically possible, due to the low resting $\operatorname{Hct}_{\text {cap }}(22 \%)$ and the reported increases seen with exercise. Even the maximum observed increase in total $[\mathrm{Hb}+\mathrm{Mb}]$ of $34.5 \%$ (reflecting a doubling of tissue $[\mathrm{Hb}]$ and an increase in $\mathrm{Hb}$ contribution to LAP from $32 \%$ to $49 \%$ ) in one subject is theoretically possible, representing an approximate doubling of capillary hematocrit (i.e., approaching systemic Hct). 
Figure 4-1 Concentration and light absorbing potential (LAP) for different capillary densities

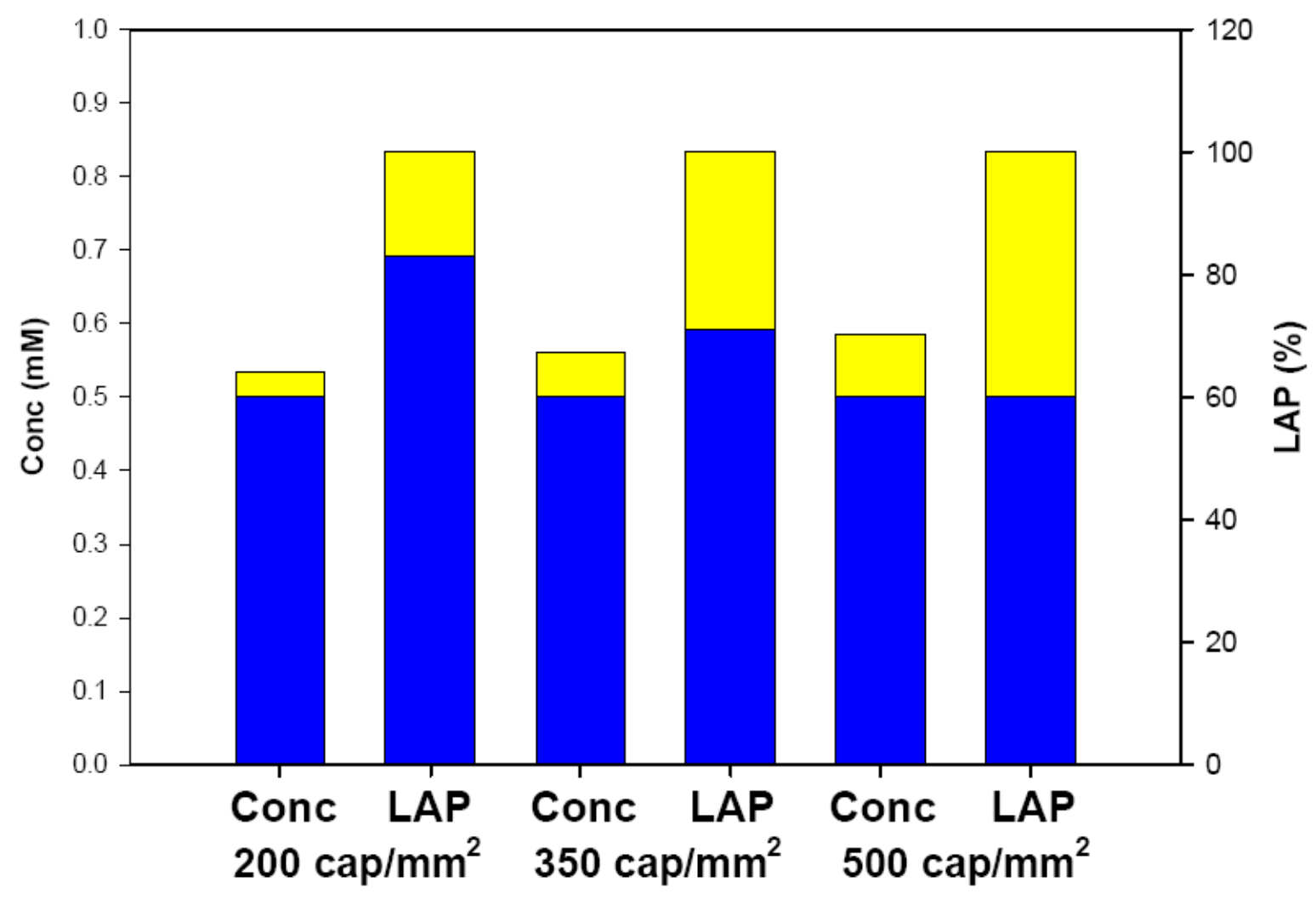

Concentration (Conc) and light absorbing potential (LAP) of tissue [Mb] and vascular $[\mathrm{Hb}]$ at three theoretical capillary densities. $[\mathrm{Mb}]$ is represented by the dark shaded area and $[\mathrm{Hb}]$ is represented by the lighter shade. As the capillary densities varied over a range from 200-500 cap/ $/ \mathrm{mm}^{2}$, the contributions of $[\mathrm{Mb}]$ and $[\mathrm{Hb}]$ changed in a similar fashion for both concentration and LAP. [Mb] was assumed to be $0.5 \mathrm{mM}$ (van Beek- Harmsen et al, 2004) while [Hb] was based on an assumed resting $\mathrm{Hct}_{\text {cap }}$ of $20 \%$ at each of the capillary densities. See methods for complete calculations. 


\section{Figure 4-2 LAP of [Hb] and [Mb] calculated for several mammalian species and muscles}

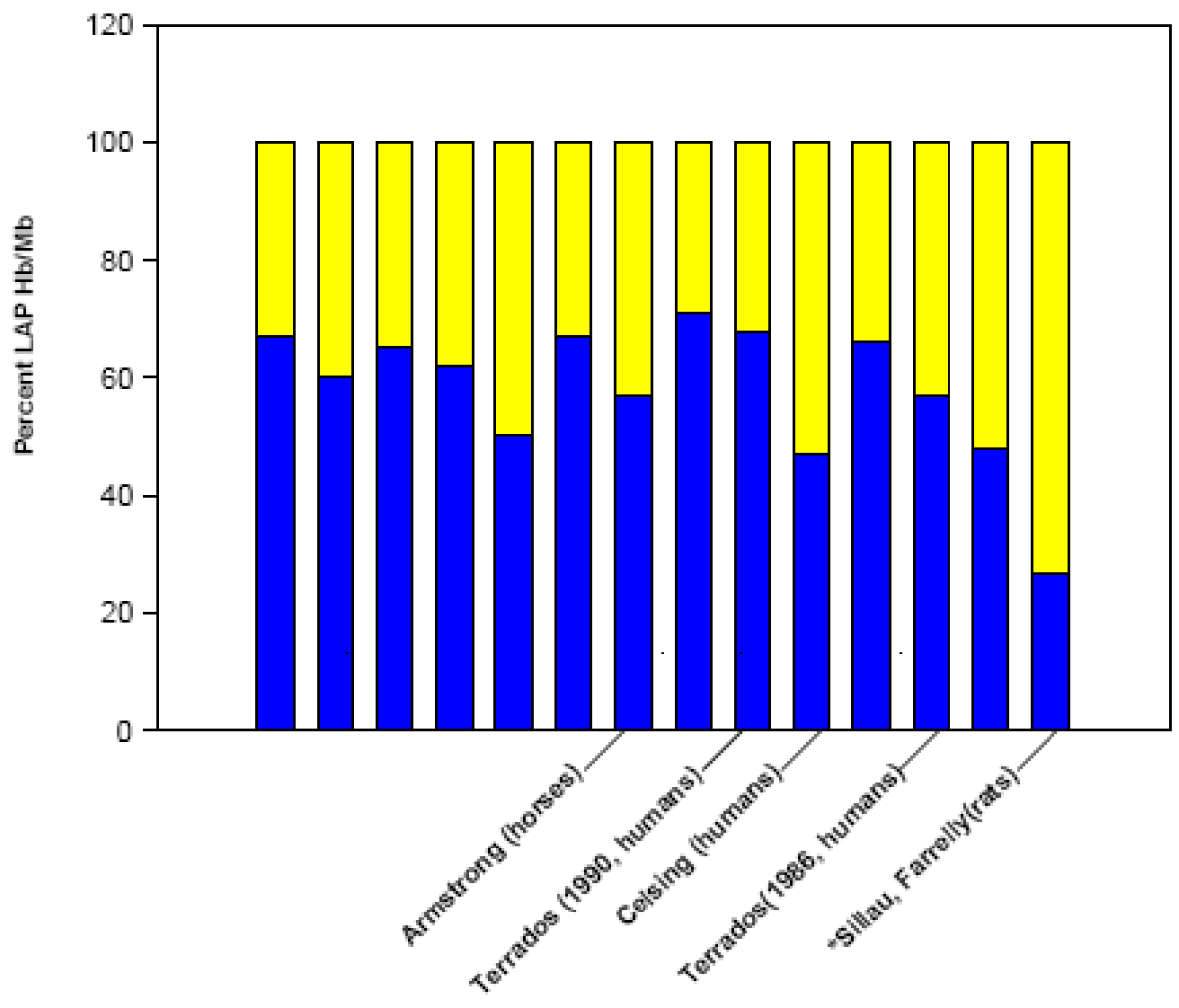

Relative LAP of $[\mathrm{Hb}]$ and $[\mathrm{Mb}]$ calculated for different muscles. $[\mathrm{Mb}]$ is represented by the dark shaded area and $[\mathrm{Hb}]$ is represented by the lighter shade. Note that estimated LAP for $[\mathrm{Mb}]$ was $\geq 50 \%$ for all muscles but those of the rat, which showed the lowest contribution from $[\mathrm{Mb}]$ among the species at $\sim 30 \%$, still substantially higher than the assumed $10 \%$ contribution (Seiyama, 1987). ${ }^{*}[\mathrm{Mb}]$ and capillary density were obtained from separate sources. 
Figure 4-3 Calculated vs measured $[\mathrm{Mb}+\mathrm{Hb}]$ concentrations and light absorbing potential (LAP)

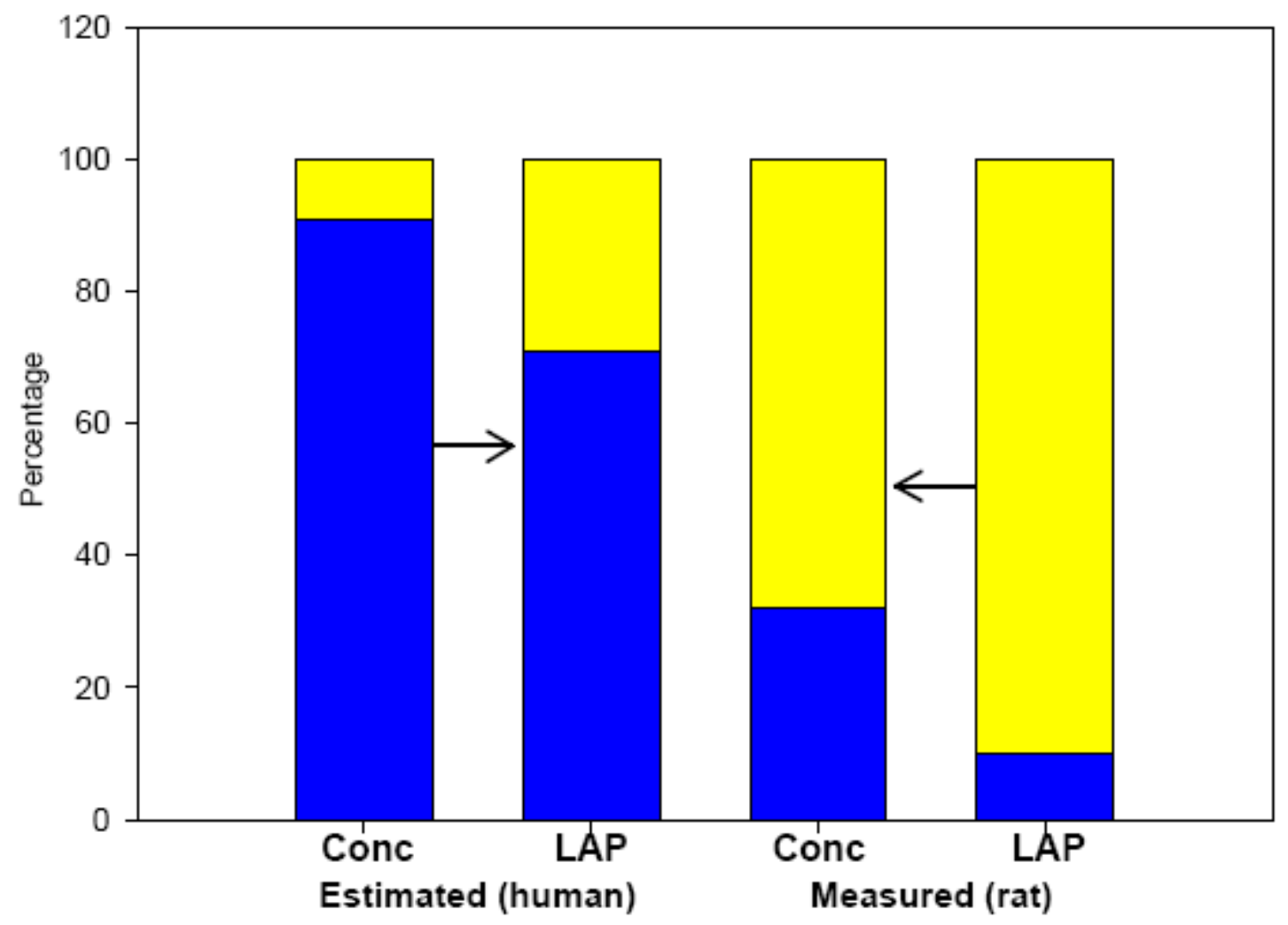

Estimated (this paper) vs. measured (Seiyama et al 1988) relative concentration and LAP of tissue $[\mathrm{Mb}]$ and vascular $[\mathrm{Hb}]$. Estimated concentrations and LAP were derived from an average capillary density of $350 \mathrm{cap} / \mathrm{mm}^{2}$ and $[\mathrm{Mb}]$ concentration of $0.5 \mathrm{mM}$. The measured concentration was calculated from the LAP from Seiyama et al (1988). Calculated contribution of $[\mathrm{Mb}]$ to LAP $(\geq 60 \%)$ for human muscle is substantially higher than that reported by Seiyama et al (1988) for rat hindlimb (10\%). 
Figure 4-4 The effect of changes in [Hb] on changes in total $[\mathrm{Hb}+\mathrm{Mb}]$ during exercise

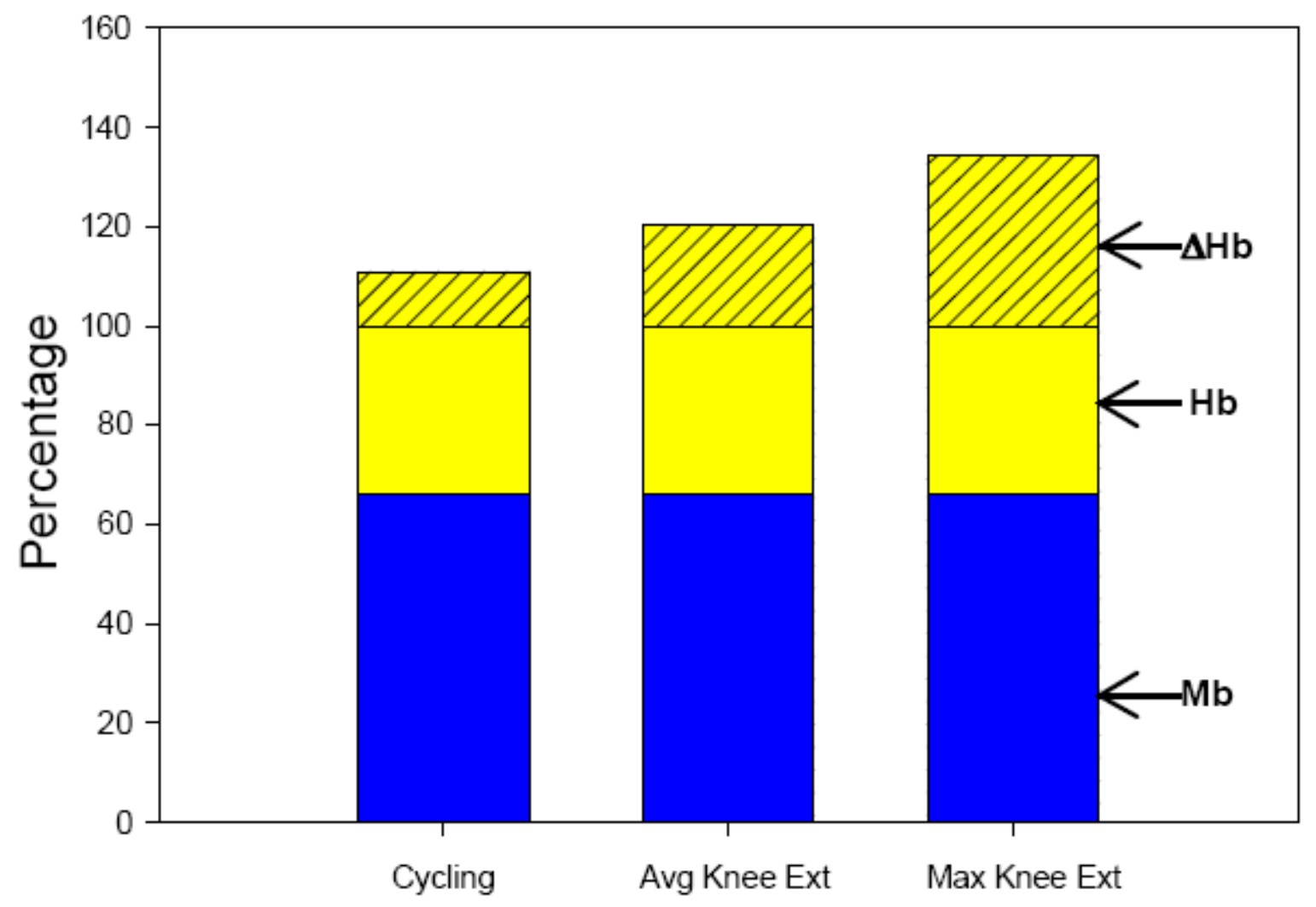

Contribution of $[\mathrm{Hb}]$ to the total $[\mathrm{Hb}+\mathrm{Mb}]$ during cycle and knee extension exercise in humans. The average increase in total $[\mathrm{Hb}+\mathrm{Mb}]$ for incremental cycling at $60 \mathrm{rpm}$ and $100 \mathrm{rpm}(10.9 \%)$ and the average (20.4\%) and maximal (34.5\%) values for knee extension exercise from Table 1 were added to the LAP from the present study in Fig 4-3. Assuming all of the increase was due to increased [Hb], this represented an approximate increase in total $[\mathrm{Hb}]$ of $\sim 29 \%$ for incremental cycling, $\sim 54 \%$ for the average of knee extension exercise and $\sim 91 \%$ for maximum knee extension. Under any of these conditions the increase in the LAP of $[\mathrm{Hb}]$ is physiologically possible, due to the available range of increase in $\mathrm{Hct}_{\text {cap }}$ from rest values near $\sim 22 \%$ to a systemic Hct of $45 \%$. 
Table 4-1 Percent change in total $[\mathrm{Hb}+\mathrm{Mb}]$ during knee extension and incremental cycling tests

\begin{tabular}{|c|c|c|c|}
\hline Subject & Knee $^{\text {A }}$ & \multicolumn{2}{|c|}{ CyclingB $^{\mathbf{B}}$} \\
\hline & & $\mathbf{6 0} \mathrm{rpm}$ & $\mathbf{1 0 0} \mathbf{~ r p m}$ \\
\hline 1 & 34.5 & 3.1 & 17.7 \\
\hline 2 & 31.7 & & \\
\hline 3 & 28.2 & 30.0 & 19.6 \\
\hline 4 & 19.4 & 1.8 & 9.5 \\
\hline 5 & 19.2 & & \\
\hline 6 & 13.7 & & \\
\hline 7 & 9.8 & 0.3 & 4.6 \\
\hline 8 & 6.9 & & \\
\hline 9 & & 22.8 & 7.3 \\
\hline 10 & & 18.0 & 12.0 \\
\hline 11 & & 13.7 & 6.5 \\
\hline 12 & & 9.0 & 11.4 \\
\hline 13 & & 2.7 & 5.3 \\
\hline Mean & 20.4 & 11.3 & 10.4 \\
\hline Std Dev & 10.2 & 10.5 & 5.3 \\
\hline
\end{tabular}

A Data from Lutjemeier et al, 2008, B Data from Ferreira et al, 2005 


\section{CHAPTER 5 - Discussion}

To our knowledge, this is the first study to examine and distinguish the potential quantitative contributions of $\mathrm{Hb}$ and $\mathrm{Mb}$ to the NIRS signal based on chemical and morphometric analysis of skeletal muscle. Using physiological estimates of capillary [Hb] and tissue $[\mathrm{Mb}]$, these data suggest that LAP of Mb likely contributes $\geq 50 \%$ of the NIRS signal for many mammalian muscles, including those of humans. In addition, the increase in total $[\mathrm{Hb}+\mathrm{Mb}]$ seen with exercise in humans can be explained in the context of increased capillary hematocrit from resting values. Finally, the specific muscle(s) being measured may significantly influence the contribution of tissue $[\mathrm{Mb}]$ to the NIRS signal.

\section{Assumptions}

The following assumptions were made in order to calculate the $\mathrm{Hb}$ and $\mathrm{Mb}$ contributions to NIRS: muscle capillary density, systemic concentration of [Hb], relative contribution of $\mathrm{Hb}$ and $\mathrm{Mb}$ molecules to the LAP based on heme groups (4:1), average skeletal muscle [Mb] concentration and capillary hematocrit at rest.

To assess the affect of capillary density on the relative contribution of $\mathrm{Hb}$ and $\mathrm{Mb}$ to total heme concentration and LAP, a range of capillary densities $\left(200-500 \mathrm{cap} / \mathrm{mm}^{2}\right)$ was evaluated. Similar capillary densities have been measured in human skeletal muscle [e.g., $286 \mathrm{cap} / \mathrm{mm}^{2}$ (Celsing, 1988), 300-550 cap/mm² (Terrados, 1986, Terrados, 1990)]. A higher capillary density has the potential to increase the LAP of $\mathrm{Hb}$ in skeletal muscle. Figure 4-1 shows that the concentration and LAP of $\mathrm{Hb}$ increased, while the relative LAP of Mb decreased, as capillary density increased at constant tissue $[\mathrm{Mb}]$. However, even with a gradual decrease in the relative 
LAP of $\mathrm{Mb}$ as capillary density increased, the assumed $[\mathrm{Mb}]$ of $0.5 \mathrm{mM}$ represents more than $50 \%$ of the LAP even at the highest capillary density of $500 \mathrm{cap} / \mathrm{mm}^{2}$.

Both $\mathrm{Hb}$ and $\mathrm{Mb}$ facilitate the transfer of oxygen in skeletal muscle, but have different chemical structures. A $\mathrm{Hb}$ molecule has 4 heme units while $\mathrm{Mb}$ has only one heme. This significant difference was used in the present study to calculate LAP. Each heme can absorb light photons, giving $\mathrm{Hb}$ four times more potential per molecule to absorb light than $\mathrm{Mb}$. This difference in LAP led to the assumption that $\mathrm{Hb}$ would contribute significantly more to the NIRS signal than $\mathrm{Mb}$, which concurs with some of the current literature (Mancini et al, 1994, Seiyama et al, 1988).

An average muscle $[\mathrm{Mb}]$ of $0.5 \mathrm{mM}$ was used as the default value based on van BeekHarmsen et al (2004). These authors found that $[\mathrm{Mb}]$ values ranged from $0.25-0.67 \mathrm{mM}$ in healthy human rectus femoris muscle in both females and males. $[\mathrm{Mb}]$ concentrations were higher in type I fibers than type II fibers for both male and female human subjects, and females tended to be higher for both fiber types. A higher $[\mathrm{Mb}]$ has the potential to accommodate the increased $\mathrm{DO}_{2}$ needs in Type I fibers which are highly oxidative and tend to have a higher capillary and mitochondrial density. Terrados et al $(1986,1990)$ reported $[\mathrm{Mb}]$ in human skeletal muscle of 0.48-0.56 mM, similar to values from van Beek-Harmsen et al (2004). [Mb] in the rat soleus has been measured at $\sim 0.3 \mathrm{mM}$ (van Beek-Harmsen et al, 2004) and $0.26 \mathrm{mM}$ (Hickson et al, 1981), just over half of the values for human muscle reported by van BeekHarmsen (2004). The varying [Mb] concentrations as a function of gender, muscle fiber type and species have the potential to affect the percent contribution of $\mathrm{Hb}$ and $\mathrm{Mb}$ to the total $[\mathrm{Hb}+\mathrm{Mb}]$ NIRS signal and should be taken into careful consideration when interpreting data. 
$\mathrm{Mb}$ concentrations in the studies cited above were measured with varying techniques. Chemical assays are commonly used to measure $[\mathrm{Mb}]$ concentration. One common assay determines the concentration of $[\mathrm{Mb}]$ in tissue samples based on light absorption in the visible range (530-570 nm) (Warriss, 1979, Reynafarje, 1963, Terrados et al, 1990, Celsing et al, 1988, Terrados et al, 1986). Van Beek-Harmsen et al (2004) measured [Mb] concentration by staining tissue samples for $\mathrm{Mb}$. The stained samples were then viewed under a microscope equipped with a specific filter and light absorption of $\mathrm{Mb}$ and the concentration of [Mb] was then determined. Marcinek et al (2007) used gel-electrophoresis to measure [Mb] concentration. Marcinek et al (2007) used another method to determine $[\mathrm{Mb}]$ concentration and the resulting LAP. Using the second derivative of the absorptions of $\mathrm{Hb}$ and $\mathrm{Mb}$, the wavelengths at which the signal was $100 \% \mathrm{Hb}$ or $100 \% \mathrm{Mb}$ was determined. This then allows for the determination of the percent contribution of $\mathrm{Hb}$ and $\mathrm{Mb}$ between these two wavelengths for a given tissue sample. Thus, there are multiple ways to measure $[\mathrm{Mb}]$ concentration. However, to our knowledge there has not been an assessment to determine discrepancies among these various techniques to measure $[\mathrm{Mb}]$ concentration.

To correct for the reduced capillary hematocrit at rest relative to systemic hematocrit the value of 0.5 was used, derived from direct observations of the resting capillary Hct of $\sim 22 \%$ and systemic Hct of $\sim 45 \%$ (Kindig and Poole, 2001, Russell et al, 2003, Kindig and Poole, 1998). Other resting capillary Hct in the literature have ranged from $\sim 11-13 \%$ (Desjardins and Duling, 1990) to $32 \%$ (Richardson et al, 2003). The resting capillary Hct used here $(22 \%)$ is one of the larger values found in the literature. If this value overestimates the contribution of [Hb], this would imply that $[\mathrm{Mb}]$ may contribute even more to the NIRS signal than estimated in this study. 
The observed reduced capillary Hct at rest relative to the systemic circulation is thought to be due at least in part to the Fahraeus effect. The Fahraeus effect describes how RBCs tend to move faster and stay in the middle of larger vessels, rather than at the edges where there is more plasma. When bifurcations are encountered, this Fahraeus affect results in heterogeneous flow distribution, and greater contribution of plasma than RBCs to the daughter vessel flow resulting in a reduction in tube Hct. With each bifurcation there is a progressive reduction in tube Hct until the capillary bed is reached (Gaehtgens et al, 1978, Pries and Secomb, 2003). With the onset of exercise, arterioles and associated downstream networks are recruited. The resulting increase in blood flow is characterized by reduced heterogeneity of RBC flow, leading to less reduction in Hct from artery to capillary. This is seen in the NIRS as an increase from rest to exercise in total $[\mathrm{Hb}+\mathrm{Mb}]$ (Frisbee, 1998).

Another possible explanation for the reduced capillary tube Hct at rest is the role of the luminal glycocalyx in the capillary. Desjardins and Duling (1990) suggested that a reduced capillary Hct may be due to the interaction of plasma with the luminal glycocalyx, causing a retardation of plasma relative to RBCs. Capillaries in the hamster cremaster muscle were perfused with heparinase to remove part of the luminal glycocalyx and any changes in capillary tube Hct were observed. Heparinase increased capillary tube hematocrit almost three fold ( $270 \%$ ) without affecting RBC velocity. They concluded that heparinase altered the luminal surface of the capillary causing a decrease in the thickness of the plasma layer, which effectively increased capillary tube Hct. Thus, the endothelial cell surface may have a significant influence on capillary rheology and oxygen delivery.

\section{Attempts to Distinguish Mb from Hb contribution to NIRS}

Conflicting results have been obtained from the few studies which have attempted to 
ascertain the relative contributions of tissue $\mathrm{Mb}$ and microvascular $\mathrm{Hb}$ to NIRS signals. In one study, Mancini et al (1994) combined ${ }^{1} \mathrm{H}-\mathrm{MRS}$ with continuous wave NIRS in a variety of conditions in humans. During forearm exercise, there was an association between decreases in deep venous $\mathrm{O}_{2}$ blood saturation and tissue oxygenation by NIRS, although the quality of the relationship varied among subjects, with 2 of 4 showing a linear response while the response in the other 2 subjects was curvilinear. During submaximal plantar flexion exercise, in 3 of 4 subjects no $\mathrm{Mb}$ desaturation was detected by ${ }^{1} \mathrm{H}-\mathrm{MRS}$, although NIRS saturation decreased by $80 \%$. At peak exercise, $\mathrm{Mb}$ desaturation was seen in 3 of 3 subjects while NIRS desaturation reached $71 \%$. From these results the authors concluded that the NIRS signals were primarily derived from hemoglobin and not myoglobin.

In contrast, Tran et al (1999), combining similar technologies, arrived at the opposite conclusion, i.e., that most of the NIRS signals originated with $\mathrm{Mb}$, not $\mathrm{Hb}$. Cuffing of the lower leg to produce ischemia resulted in increases in NIRS deoxygenation which showed a similar time course as the increase in deoxy-Mb by ${ }^{1} \mathrm{H}-\mathrm{MRS}$. During exercise, both NIRS and deoxy$[\mathrm{Mb}]$ by ${ }^{1} \mathrm{H}-\mathrm{MRS}$ increased (although not with the same time course). However, deoxy-[Hb] by ${ }^{1}$ H-MRS only showed minimal changes ( $10 \%$ increase) with cuff occlusion, and no change during exercise. While the explanation for the discrepancies between the findings of these studies is unclear, both suffer from detection problems using ${ }^{1} \mathrm{H}-\mathrm{MRS}$. Specifically, Mancini et al (1994) found no desaturation of Mb during submaximal exercise, yet other labs (Richardson et al, 1995; Mole et al, 1999) have clearly shown that Mb detectably and significantly desaturates during even moderate exercise. In addition, one possible explanation for the apparent lack of desaturation of $\mathrm{Mb}$ during cuff occlusion following exercise in the study of Mancini et al (1994) is the observation that the cuff incompletely occluded blood flow, resulting in a noticeable 
increase in total $[\mathrm{Hb}+\mathrm{Mb}]$ (denoted as 'blood volume'). This influx of presumably oxygenated blood could have been sufficient to minimize desaturation of $\mathrm{Mb}$ during the occlusion, which would have contributed to the authors' conclusion that $\mathrm{Mb}$ desaturation contributed little to the NIRS signals in their studies. With regard to detection of $\mathrm{Hb}$ by ${ }^{1} \mathrm{H}-\mathrm{NMR}$, Wang et al (1993) showed that only $16 \%$ of $\mathrm{Hb}$ present in a suspension of intact red blood cells was NMR visible. Thus, it is likely that the results of Tran et al (1999) significantly underestimated the changes in $\mathrm{Hb}$ saturation by a factor of almost 6 fold $(100 / 16=5.88)$, which contributed to their conclusion that most of the NIRS signal originated from $\mathrm{Mb}$. Thus, unfortunately, in both these studies methodological problems and concerns preclude rigorous conclusions being drawn regarding the relative contribution of $\mathrm{Mb}$ to the NIRS signal.

In a third, frequently cited study by Seiyama et al (1988), the authors found that $\mathrm{Mb}$ contributed $<10 \%$ to the total NIRS signal of the rat hindlimb. Fig $4-3$ shows the LAP of $[\mathrm{Hb}]$ and $[\mathrm{Mb}]$ across various species, including the rat. This figure is based on studies in which capillary densities and $[\mathrm{Mb}]$ were reported for the same muscle, except that data for the rat was calculated using capillary densities from Farrelly et al (1992) and [Mb] from Sillau et al (1977). The $[\mathrm{Mb}]$ of $0.3 \mathrm{mM}$ in the soleus has the potential to contribute $\sim 50 \%$ to the NIRS signal, while the $[\mathrm{Mb}]$ of $0.1 \mathrm{mM}$ in the gastrocnemius has the potential to contribute $\sim 30 \%$ to the NIRS signal (Fig 4-3). These values are substantially higher than the contribution of $\leq 10 \%$ observed by Seiyama et al (1988). The low contribution by [Mb] reported by Seiyama et al (1988) likely arose from the muscle group being measured, the white vastus in the rat hindlimb. Hickson et al (1981) measured $[\mathrm{Mb}]$ in the white vastus, red vastus and soleus in the rat. They found that the white vastus had $\sim 0.5 \mathrm{mg} / \mathrm{g}$ of $\mathrm{Mb}(\sim 0.034 \mathrm{mM})$, the red vastus had $5.0 \mathrm{mg} / \mathrm{g}(\sim 0.34 \mathrm{mM})$ and the soleus had $3.7 \mathrm{mg} / \mathrm{g}(\sim 0.25 \mathrm{mM})$. It is probable that Seiyama et al (1988) were measuring 
$[\mathrm{Hb}]$ and $[\mathrm{Mb}]$ primarily in the superficial white vastus of the rat hindlimb. Since in the rat the white vastus is significantly lower in $[\mathrm{Mb}]$ than the red vastus and soleus, this suggests that the white vastus from the rat hindlimb is an inappropriate representation of the contribution of $\mathrm{Mb}$ to the NIRS signal when compared to human vastus lateralis and other limb muscles.

\section{Increase in total $[\mathrm{Hb}+\mathrm{Mb}]$ with exercise}

Although $[\mathrm{Mb}]$ may contribute $\geq 50 \%$ to the NIRS signal in human quadriceps muscle, increases in muscle blood flow and capillary Hct occur with exercise, resulting in an increase in tissue $[\mathrm{Hb}]$ and its contribution to the NIRS signal. Following the onset of exercise or vasodilation capillary Hct has been reported to increase with increasing flow to levels such as 27\% (Kindig and Poole, 2001) or 30\% (Desjardins and Duling, 1990), resulting in increased capillary [Hb] with exercise (Richardson et al, 2003). Table 4-1 shows the percent change of total $[\mathrm{Hb}+\mathrm{Mb}]$ during knee extension (Lutjemeier et al, 2006) and incremental cycling tests (Ferreira et al, 2005). The percent change varied among the subjects for each mode of exercise; however, subjects that were measured in both tests appeared to have similar values between the two modes [N.B. Different muscles were examined in the two studies; the vastus lateralis in the study of Ferreira et al (2005) and the rectus femoris in that by Lutjemeier et al (2006)]. Fig 4-4 demonstrates how these changes in total $[\mathrm{Hb}+\mathrm{Mb}]$ can be explained in the context of the present study. In this figure the assumption is made that the change in total $[\mathrm{Hb}+\mathrm{Mb}]$ is coming entirely from the change in $[\mathrm{Hb}]$. The average percent increase in total $[\mathrm{Hb}+\mathrm{Mb}]$ during the incremental cycling test $(\sim 11 \%)$ represents an increase of approximately one third of the estimated $[\mathrm{Hb}]$ at rest (i.e., $\mathrm{Hct}_{\text {cap }}$ increases from $22 \%$ to $29 \%$ ) whereas the average percent change in total $[\mathrm{Hb}+\mathrm{Mb}]$ during the knee extension tests $(\sim 20 \%)$, represents an increase of $\sim 50 \%$ of the resting

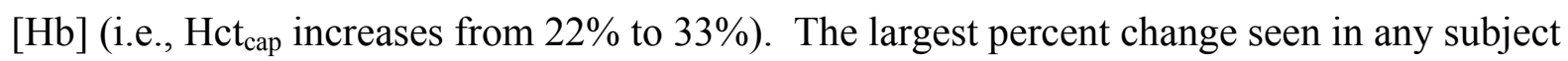


( $34 \%)$ represents a near doubling of the [Hb] signal (i.e., Hct cap increases from $22 \%$ to $44 \%$ ).

The subject that produced this large change was an elite tri-athlete, who likely would possess a greater capillary density, which might explain why these changes may be higher than changes in capillary Hct reported in the literature (Kindig and Poole, 2001 and Desjardins and Duling, 1990). Even considering this extreme change, under all these conditions the increase in the capillary $[\mathrm{Hb}]$ as the underlying mechanism for increase in total $[\mathrm{Hb}+\mathrm{Mb}]$ is physiologically possible, due to the low predicted resting $\mathrm{Hct}_{\text {cap }}$ and the potential for increase with exercise.

\section{Implications of increased [Mb] contribution to NIRS}

It is currently unclear what the implications are for greater relative contribution of $\mathrm{Mb}$ to the NIRS signals in humans. As noted above, most studies/laboratories have assumed, based on the studies discussed above (Seiyama et al., 1988; Mancini et al., 1994), that Mb contribution was negligible to the NIRS signals, so that changes in the NIRS signals were attributed solely to changes in $\mathrm{Hb}$ content and saturation in the tissue being examined. With regards to current applications of NIRS to evaluate exercise and reactive hyperemia responses, a greater contribution of $\mathrm{Mb}$ could potentially affect the interpretation of either the absolute values associated with the changes, and/or the meaning of the changes from a temporal (kinetic) perspective. Muscle $\mathrm{VO}_{2}$ has been estimated with NIRS at rest and during exercise (De Blasi et al, 1994) and the contribution of $\mathrm{Mb}$ and $\mathrm{Hb}$ to the signal may be crucial in determining the $\mathrm{VO}_{2}$. Each mmole of $\mathrm{Hb}$ is able to carry 4 mmoles of oxygen, while 1 mmole of Mb can carry 1 mmole of oxygen. Thus, if the entire signal is coming from $\mathrm{Mb}$ then the $\mathrm{VO}_{2}$ value will only be $\sim 1 / 4$ of the value if the NIRS signal was coming entirely from $\mathrm{Hb}$. Along these lines, an important question to be answered is, "Does the relative contribution of deoxy-[Hb] and deoxy$[\mathrm{Mb}]$ to the total deoxy signal remain constant across the range of exercise intensities?" This 
remains to be elucidated.

With regard to temporal considerations, one critical question is whether or not vascular $\mathrm{Hb}$ and intracellular $\mathrm{Mb}$ saturate or desaturate with changes in muscle metabolic rate with the same time course. If, following exercise onset, $\mathrm{Mb}$ desaturated with a different time course than $\mathrm{Hb}$, this could potentially invalidate a recently developed approach to estimating capillary blood flow kinetics, based on the assumption that the temporal changes in the NIRS deoxy signal could be attributed to deoxy-[Hb] (Ferreira et al, 2005). However, while temporal data on $\mathrm{Mb}$ desaturation during exercise is scant, Richardson et al (1995) noted that within 20 sec they could detect desaturation of $\mathrm{Mb}$ by ${ }^{1} \mathrm{H}-\mathrm{MRS}$, which is the time course noted by many labs for the kinetics of increase in the NIRS deoxy signal (Ferreira, 2005; Grassi, 2003; DeLorey, 2003). Given that estimates of the mean time for diffusion of $\mathrm{O}_{2}$ from $\mathrm{RBC}$ to mitochondria are around $1 \mathrm{sec}$ or less, it would suggest that the whole diffusion pathway, including vascular $\mathrm{Hb}$ and intracellular $\mathrm{Mb}$, desaturate with a similar time course (Gayeski et al, 1988). If true, then a potentially greater contribution of $\mathrm{Mb}$ to the NIRS deoxy signal would not invalidate the approach of estimating capillary blood flow described above.

Our data and conclusions are similar to those recently reported by Marcinek et al (2007), who were able to differentiate $\mathrm{Mb}$ from $\mathrm{Hb}$ contributions to NIRS by examining the second derivative of the spectra across a wide range of NIRS wavelengths. They found that, in human first dorsal interosseous muscle, $\mathrm{Hb}$ contributed $\sim 21 \%$ to the NIRS signal, whereas in mouse hindlimb, Hb contributed $86.5 \%$. Their data confirm both our prediction regarding a significant contribution by $\mathrm{Mb}$ to NIRS in human muscle, and the inappropriateness of rodent hindlimb (Seiyama et al, 1988, Marcinek et al, 2007) to determine the relative distributions of $\mathrm{Hb}$ and $\mathrm{Mb}$ in human muscle. 


\section{Limitations}

In the present study the values of the variables used in the calculations were based upon current literature. Calculations for tissue $[\mathrm{Hb}]$ were based on capillary data; however $\mathrm{Hb}$ is also present in arterioles and venules which will also contribute to the NIRS signal, and due to a reduced Fahraeus effect will have a Hct value higher than that seen in the capillaries at rest. Thus the "real" average tissue Hct (as seen by NIRS) will likely be higher than that estimated for the capillaries, closer to that of systemic Hct. In addition, the concentrations and LAPs of Mb were based on an average value of $0.5 \mathrm{mM}$ (van Beek-Harmsen, 2004), which is known to vary according to gender, muscle, fiber type and species.

\section{Future Studies}

Given the above uncertainties, at this time the relative contribution of $\mathrm{Hb}$ and $\mathrm{Mb}$ to the NIRS signal can not be stated precisely for a given individual. In order to further refine this prediction, future research should focus on the following areas. It will be necessary to directly measure tissue $[\mathrm{Mb}]$ and capillary density by muscle biopsy in the same subject and muscle of interest. Also, the time course of desaturation of $\mathrm{Mb}$ and $\mathrm{Hb}$ during exercise should be simultaneously determined. Further, exercise intensity may affect the relative desaturation of $\mathrm{Hb}$ and $\mathrm{Mb}$ differently, which would potentially alter the relative contribution of deoxy-[Hb] and deoxy-[Mb] to NIRS at any given point during exercise. Despite the potential technical limitations noted above, the collaborative use of ${ }^{1} \mathrm{H}-\mathrm{MRS}$ and NIRS remains a potent approach with which to quantify changes in $\mathrm{Mb}$ and $\mathrm{Hb}$ during exercise.

\section{Conclusion}


The aim of the present study was to estimate, using histochemical and morphometric data in the literature, the relative contributions of $\mathrm{Hb}$ and $\mathrm{Mb}$ to the NIRS signal, with special application to human skeletal muscle. These results predict that Mb likely contributes $\geq 50 \%$ of the total $[\mathrm{Hb}+\mathrm{Mb}]$ NIRS signal for most mammalian muscles, including those of the human leg. However, rodent (either rat or mouse) hindlimb is not a good surrogate for human skeletal muscle with regards to $[\mathrm{Hb}]$ and $[\mathrm{Mb}]$ contribution to NIRS. The increases in total $[\mathrm{Hb}+\mathrm{Mb}]$ seen in human muscle with exercise can be explained in the context of increased capillary hematocrit from resting values. Finally, the specific muscle(s) being measured with NIRS may affect the contribution of $[\mathrm{Mb}]$ to the NIRS signal. The implications of these results and the potential impact on the interpretation of the NIRS signal in humans during exercise remain to be elucidated. 


\section{References}

Armstrong, R.B., Essen-Gustavsson, B., Hoppeler, H., Jones, J.H., Kayar, S.R., Laughlin, M.H., Lindholm, A., Longworth, K.E., Taylor, C.R. and Weibel, E.R. (1992). O 2 delivery at $\mathrm{VO}_{2 \mathrm{max}}$ and oxidative capacity in muscles of Standard bred horses. J Appl Physiol, 73(6): 2274-2282.

Barbee, J.H. and Cokelet, G.R. (1971). Prediction o fblood flow in tubes with diameters as small as $29 \mu$. Microvascular Research, 3:17-21.

Buono, M.J., Miller, P.W., Hom, C., Pozos, R.S. and Kolkhorst, F.W. (2005). Skin blood flow affects in vivo near-infrared spectroscopy measurements in human skeletal muscle. Japanese Journal of Physiology, 55:241-244.

Celsing, F., Ekblom, B., Sylven, C., Everett, J. and Astrand, P.O. (1988). Effects of chronic iron deficiency anaemia on myoglobin content, enzyme activity and capillary density in the human skeletal muscle. Acta Med Scand, 223:451-457.

Chance, B., Dait, M.T., Zhang, C., Hamaoka, T. and Hagerman, F. (1992). Recovery from exercise-induced desaturation in the quadriceps muscles of elite competitive rowers. Am J Physiol 262 (Cell Physiol), 31:C766-C775.

Clark, M., Rattigan, S., Barrett, E. and Vincent, M. (2008). Last word on Point/Counterpoint: There is/is not capillary recruitment in active skeletal muscle during exercise. J Appl Physiol, 104(3):900.

Davis, S.L., Fadel, P.J., Cui, J., Thomas, G.D. and Crandall, C.G. (2006). Skin blood flow influences near-infrared spectroscopy-derived measurements of tissue oxygenation during heat stress. J Appl Physiol, 100:221-224. 
De Blasi, R.A., Ferrari, M., Natali, A., Conti, G., Mega, A., and Gasparetto, A. (1994). Noninvasive measurement of forearm blood flow and oxygen consumption by nearinfrared spectroscopy. J Appl Physiol, 76(3):1388-1393.

DeLorey, D.S., Kowalchuk, J.M. and Paterson, D.H. (2003). Relationship between pulmonary O2 uptake kinetics and muscle deoxygenation during moderate-intensity exercise. J Appl Physiol, 95(1):113-120.

Desjardins, C. and Duling, B.R. (1990). Heparinase treatment suggests a role for the endothelial cell glycocalyx in regulation of capillary hematocrit. Am J Physiol, 258(3 Pt 2):H647654.

Farrelly, C.A. and Snyder, G.K. (1992). Capillarity in rat skeletal muscle: effects of rapid freezing versus perfusion fixation. Biotechnic and Histochemistry, 67(5):315-320.

Ferrari, M., Cettolo, V. and Quaresima, V. (2006). Light source detector spacing of nearinfrared-based tissue oximeters and the influence of skin blood flow. J Appl Physiol, 100:1426-1427.

Ferreira, L.F., Lutjemeier, B.J., Townsend, D.K., Barstow, T.J. (2005). Effects of pedal frequency on estimated muscle microvascular O2 extraction. European Journal of Applied Physiology, 96:558-563.

Frisbee, J.C. (1998). Striated muscle microvascular hematocrit: the increase from rest to contraction. Microvascular Research, 55:184-186.

Gaehtgens, P., Albrecht, K.H. and Kreutx, F. (1978). Fahraeus effect and cell screening during tube flow of human blood. I. Effect of Variation of flow rate. Biorheology, 15:147-154. 
Garry, D.J., Ordway, G.A., Lorenz, J.N., Radford, N.B., Chin, E.R., Grange, R.W., Bassel-Duby, R. and Williams, R.S. (1998). Mice without myoglobin. Nature, 395(29):905-908.

Gayeski, T.E.J., Federspiel, W.J. and Honig, C.R. (1988). A graphical analysis of the influence of red cell transit time, carrier-free layer thickness, and intracellular $\mathrm{PO}_{2}$ on blood-tissue $\mathrm{O}_{2}$ transport. Advances in Experimental Medicine and Biology, 222:25-35.

Gödecke, A., Flögel, U., Zanger, K., Ding, Z., Hirchenhain, J., Decking, U.K.M. and Schrader, J. (1999). Disruption of myoglobin in mice induces multiple compensatory mechanisms. Proc Natl Acad Sci, 96:10495-10500.

Grassi, B., Quaresima, V., Marconi, C., Ferrari, M. and Cerretelli, P. (1999). Blood lactate accumulation and muscle deoxygenation during incremental exercise. J Appl Physiol, 87(1):348-355.

Grassi, B., Pogliaghi, S., Rampichini, S., Quaresima, V., Ferrari, M., Marconi, C. and Cerretelli, P. (2003). Muscle oxygenation and pulmonary gas exchange kinetics during cycling exercise on-transitions in humans. J Appl Physiol ,95(1):149-158.

Groebe, K. and Thews, G. (1990). Calculated intra- and extracellular $\mathrm{PO}_{2}$ gradients in heavily working red muscle. Am J Physiol 259 (Heart Circ Physiol), 28:H84-H92.

Hickson, R.C. (1981). Skeletal muscle cytochrome $c$ and myoglobin, endurance and frequency of training. J Appl Physiol Respirat Environ Exercise Physiol, 51(3):746-749.

Honig, C.R., Odoroff, C.L., and Frierson, J.L. (1980). Capillary recruitment in exercise: rate, extent, uniformity, and relation to blood flow. Am J Physiol 238 (Heart Circ Physiol), 7: H31-42.

Horecker, B.L. (1943). The absorption spectra of hemoglobin and its derivatives in the visible and Near infrared regions. J Biol Chem, 148:173-183 
Hueber, D.M., Franceschini, M.A., Ma, H.Y., Zhang, Q., Ballesteros, J.R., Fantini, S., Wallace, D., Ntziachristos, V. and Chance, B. (2001). Non-invasive and quantitative near-infrared haemoglobin spectrometry in the piglet brain during hypoxic stress, using a frequency domain multidistance instrument. Phys Med Biol, 46:41-62.

Kindig, C.A., Poole, D.C. (1998). A comparison of the microcirculation in the rat spinotrapezius and diaphragm muscles. Microvascular Research, 55:249-259.

Kindig, C.A., Poole, D.C. (2001). Sarcomere Length-induced alterations of capillary hemodynamics in rat spinotrapezius Muscle: vasoactive vs passive control. Microvascular Research, 61:64-74.

Kindig, C.A., Richardson, T.E. and Poole, D.C. (2002). Skeletal muscle capillary hemodynamics from rest to contraction: implications for oxygen transfer. J Appl Physiol, 92(6):2513-2520.

Klitzman, B. and Duling, B.R. (1979). Microvascular hematocrit and red cell flow in resting and contracting striated muscle. Am J Physiol: Heart Circ Physiol, 6(4): H481-H490.

Krogh, A. (1919). The supply of oxygen to the tissues and the regulation of the capillary circulation. J Physiol, 457-474.

Lutjemeier B.J., Ferreira, L.F., Poole, D.C., Townsend, D. and Barstow TJ. (2008). Muscle microvascular hemoglobin concentration and oxygenation within the contractionrelaxation cycle. Respir Physiol Neurobiol, 160(2):131-8.

Mancini, D.M., Bolinger, L., Li, H., Kendrick, K., Chance, B. and Wilson, J.R. (1994). Validation of near-infrared spectroscopy in humans. J Appl Physiol, 77(6):2740-2747. 
Marcinek, D.J., Amara, C.E., Matz, K., Conley, K.E. and Schenkman, K.A. (2007). Wavelength shift analysis: A simple method to determine the contribution of hemoglobin and myoglobin to in vivo optical spectra. Applied Spectroscopy, 61(6):665-669.

McDonald, M.J., Tarnopolsky, M.A., Green, H.J. and Hughson, R.L. (1999). Comparison of femoral blood gases and muscle near-infrared spectroscopy at exercise onset in humans. J Appl Physiol, 86(2):687-693.

Mole, P.A., Chung, Y., Tran, T.K., Sailasuta, N., Hurd, R. and Jue, T. (1999). Myoglobin desaturation with exercise intensity in human gastrocnemius muscle. Am J Physiol Reg Integ Comp Physiol, 277:R173-R180.

Ordway, G.A. and Garry, D.J. (2004). Myoglobin: an essential hemoprotein in striated muscle. The Journal of Experimental Biology, 207:3441-3446.

Owen-Reece, H., Smith, M., Elwell, C.E. and Goldstone, J.C. (1999). Near infrared spectroscopy. British Journal of Anasthesia, 82(3):418-426.

Poole, D.C., Musch, T.I., and Kindig, C.A. (1997). In vivo microvascular structural and functional consequences of muscle length changes. Am J Physiol Heart Circ Physiol, H2107-H2114.

Pries, A.R. and Secomb, T.W. (2003). Rheology of the microcirculation. Clinical Hemorheology and Microcirculation, 29:143-148.

Quaremsima, V. and Ferrari, M. (2006). Evaluation of the skin blood flow contribution to the non-invasive measurement of muscle oxygenation by near infrared spectroscopy. The Journal of Physiological Sciences, 56:267-268.

Reynafarje, B. (1963). Simplified method for the determination of myoglobin. J Lab Clin Med, 61:138-145. 
Richardson, R.S., Noyszewski, E.A., Kendrick, K.F., Leigh, J.S. and Wagner, P.D. (1995). Myoglobin $\mathrm{O}_{2}$ desaturation during exercise. J Clin Invest, 96:1916-1926.

Richardson, R.S., Poole, D.D., Knight, D.R. and Wagner, P.D. (1994). Red blood cell transit time in man: theoretical effects of capillary density. Advances in Experimental Medicine and Biology, 521-532.

Richardson, R.S., Newcomer, S.C., and Noyszewski, E.A. (2001). Skeletal muscle intracellular $\mathrm{PO}_{2}$ assessed by myoglobin desaturation: response to graded exercise. J Appl Physiol, 91:2679-2685.

Richardson, T.E., Kindig, C.A., Musch, T.I. and Poole, D.C. (2003). Effects of chronic heart failure on skeletal muscle capillary hemodynamics at rest and during contractions. J Appl Physiol, 95:1055-1062.

Richardson, R.S., Duteil, S., Wary, C., Wray, D.W., Hoff, J. and Carlier, P.G. (2006). Human skeletal muscle intracellular oxygenation: the impact of ambient oxygen availability. $J$ Physiol, 571:415-424.

Rolfe, P. (2000). In vivo Near-infrared spectroscopy. Annu Rev Biomed Eng, 02:715-754.

Russell, J.A., Kindig, C.A., Behnke, B.J., Poole, D.C. and Musch, T.I. (2003). Effects of aging in capillary geometry and hemodynamics in rat spinotrapezius muscle. Am J Physiol Heart Circ Physiol, 285:H251-H258.

Seiyama, A., Hazeki, O. and Tamura, M. (1988). Noninvasive quantitative analysis of blood oxygenation in rat skeletal muscle. J Biochem, 103:419-424.

Sillau, A.H. and Banchero, N. (1977). Effects of hypoxia on capillary density and fiber composition in rat skeletal muscle. Pflugers Archiv, 370:227-232. 
Terrados, N., Jansson, E., Sylven, C. and Kaijser, L. (1990). Is hypoxia a stimulus for synthesis of oxidative enzymes and myoglobin? J Appl Physiol, 68(6):2369-2372.

Terrados, N., Melichna, J., Sylven, C. and Jansson, E. (1986). Decrease in skeletal muscle myoglobin with intensive training in man. Acta Physiol Scand, 128:651-652.

Tran, T.K., Sailasuta, N., Kreutzer, U., Hurd, R., Chung, Y., Mole, P., Kuno, S. and Jue, T. (1999). Comparative analysis of NMR and NIRS measurements of intracellular $\mathrm{PO}_{2}$ in human skeletal muscle. Am J Physiol Reg Integ Comp Physiol, 276:R1682-R1690.

Van Beek-Harmsen, B.J., Bekedam, M.A., Feenstra, H.M., Visser, F.C. and van der Laarse, W.J. (2004). Determination of myoglobin concentration and oxidative capacity in cryostat sections of human and rat skeletal muscle fibres and rat cardiomyoctes. Histochem Cell Biol, 121:335-342.

Wang, D., Nioka, S., Wang, Z., Leigh, J.S. and Chance, B. (1993). NMR visibility studies of N$\delta$ proton of proximal histidine in deoxyhemoglobin in lysed and intact red cells. Magn Reson Med, 30:759-763.

Warriss, P.D. (1979). The extraction of haem pigments from fresh meat. J Fd Technol, 14:75-80.

Wilson, J.R., Mancini, D.M., McCully, K., Ferrare, N., Lanoce, V. and Chance, B. (1989). Noninvasive detection of skeletal muscle underperfusion with near-infrared spectroscopy in patients with heart failure. Circulation, 80:1668-1674.

Wittenberg, J.B. (1970). Myoglobin facilitated oxygen diffusion and the role of myoglobin in oxygen entry into the muscle. Physiol Rev, 50:559-636.

Wittenberg, J.B. and Wittenberg, B.A. (2003). Myoglobin function reassessed. The Journal of Experimental Biology, 206:2011-2020. 
